\title{
Meta-analyses of the efficacy of pharmacotherapies and sublingual allergy immunotherapy tablets for allergic rhinitis in adults and children*
}

\author{
Eli O. Meltzer ${ }^{1}$, Dana Wallace ${ }^{2}$, Howard S. Friedman³, Prakash Navaratnam³ \\ Erin P. Scott ${ }^{4}$, Hendrik Nolte ${ }^{5}$ \\ ' Allergy and Asthma Medical Group \& Research Center, University of California School of Medicine, San Diego, CA, USA \\ ${ }^{2}$ Nova Southeastern Allopathic Medical School, Davie, FL, USA \\ ${ }^{3}$ DataMed Solutions, New York, NY, USA \\ ${ }^{4}$ Scott Medical Communications, Tyler, TX, USA \\ ALK-Abelló, Bedminster, NJ, USA
}

Rhinology 59: 0, 0- 0, 2021

https://doi.org/10.4193/Rhin21.054

*Received for publication:

February 3, 2021

Accepted: July 31,2021

\begin{abstract}
Background: Treatment options for seasonal and perennial allergic rhinitis (SAR/PAR) include pharmacotherapies and allergy immunotherapy. These meta-analyses evaluated the effic y of pharmacotherapies and sublingual immunotherapy tablets (SLITtablets) versus placebo on nasal symptoms associated with SAR and PAR.
\end{abstract}

Methods: Randomized, double-blind, placebo-controlled trials were identified $\mathrm{f}$ om systematic PubMED/EMBASE searches through 7/18/2019 (PROSPERO protocol CRD42018105632). The primary outcome was mean numerical difference in total nasal symptom score (TNSS; 0-12) between active treatment and placebo at the end of the assessment period. Random-effects metaanalyses estimated the mean difference for each medication group weighted by the inverse of the trial variance. Publication bias assessments and sensitivity analyses were conducted.

Results: Rescue symptom-relieving pharmacotherapy was prohibited in most pharmacotherapy trials but was allowed in all SLIT-tablet trials. For adult/adolescent SAR, the mean numerical difference $(95 \% \mathrm{CI})$ in TNSS versus placebo was: intranasal corticosteroids $(\mathrm{INCS})=1.38(1.18,1.58 ; 39$ trials); combination intranasal antihistamine/INCS=1.34 (1.15, 1.54; 4 trials); intranasal antihistamines $=0.72(0.56,0.89 ; 13$ trials $)$; oral antihistamine $=0.62(0.35,0.90 ; 18$ trials $) ;$ SLIT-tablets $=0.57(0.41,0.73 ; 4$ trials $) ;$ and montelukast $=0.48(0.36,0.60 ; 10$ trials). For adult/adolescent PAR, mean difference in TNSS versus placebo $(95 \% \mathrm{Cl})$ was: INCS $=0.82$ $(0.66,0.97 ; 14$ trials); SLIT-tablets $=0.65(0.42,0.88 ; 3$ trials $)$; and oral antihistamine $=0.27(0.11,0.42 ; 3$ trials $)$. The number of eligible trials limited meta-analyses for pediatric SAR/PAR.

Conclusions: All treatments significa tly improved nasal symptoms versus placebo. SLIT-tablets provided improvement in TNSS despite access to rescue symptom-relieving pharmacotherapy. Extensive trial heterogeneity and strong indications of publication bias preclude the comparison of treatment effects among treatment classes.

Key words: glucocorticoids, histamine antagonists, montelukast, rhinitis, allergic, sublingual immunotherapy

\section{Introduction}

Allergic rhinitis (AR) has a substantial impact on patients' healthrelated quality of life ${ }^{(1,2)}$. The nasal symptoms (congestion, sneezing, itching, rhinorrhea) of AR have been shown to be associated with substantial morbidity including sleep impairment and reduction in work and school productivity ${ }^{(3,4)}$. Current treatment options for seasonal AR (SAR) and perennial AR (PAR) are primarily pharmacotherapy (including, second-generation oral or intranasal antihistamines, decongestants, intranasal corticosteroids [INCS], leukotriene receptor antagonists [LTRA]) and allergy immunotherapy (AIT) ${ }^{(5-7)}$. AIT is available in various formulations, of which sublingual immunotherapy (SLIT)-tablets are the most rigorously studied.

A small number of the pharmacotherapy trials have included 
active comparators from other treatment classes, but because there are many pharmacotherapy options for AR, there are little direct head-to-head data comparing effic $y$ among all the various treatment classes. Furthermore, there have been no head-to-head trials designed to directly compare the effic $y$ of pharmacotherapy and SLIT-tablets, partially due to the need for long-term SLIT-tablet trials to allow rescue symptomrelieving pharmacotherapy use in both placebo and active treatment groups. Thus, comparisons between the effects of all the treatment classes can only be done indirectly. Two previous meta-analyses compared the treatment effects of SLIT-tablets, oral antihistamines, INCS, and LTRA but were limited in that one analysis only included single products from varying pharmacological classes and the other analysis only included patients with SAR ${ }^{(8,9)}$. Furthermore, neither meta-analyses reported results for children with AR.

The objective of these meta-analyses was to systematically evaluate the effic $y$ of pharmacotherapy and SLIT-tablets versus placebo on nasal symptoms associated with adult/adolescent and pediatric SAR and PAR.

\section{Materials and methods}

The protocol for these meta-analyses was registered and can be accessed in PROSPERO (CRD42018105632). These meta-analyses were conducted in accordance with Preferred Reporting Items for Systematic Reviews and Meta-Analyses (PRISMA) guidelines (10).

\section{Trial eligibility criteria}

Randomized, double-blind, placebo-controlled trials that evaluated the effic $y$ of pharmacotherapies and SLIT-tablets for SAR or PAR in adults/adolescents and/or children were included in these analyses. Nasal provocation, environmental exposure unit, and cross-over trials were excluded. Additional trial eligibility criteria were the evaluation of US Food and Drug Administration (FDA)-approved doses (Supplemental Table E1), minimum pharmacotherapy assessment period of 2 weeks for SAR, and minimum pharmacotherapy assessment period of 4 weeks for PAR. There was no limit on assessment periods for the SLITtablet trials since AIT requires several weeks of treatment before an effect is observed and trials last months, rather than weeks. A reported effic y variable of total nasal symptom score (TNSS) defined as the sum or verage of scores for sneezing, rhinorrhea (or nasal discharge), congestion (or blocked nose), and nasal itching, or any combination of these symptoms scored on any scale was required for eligibility. The TNSS had to be reported in tables, figu es, or text in such a way that actual average daily sum score at the end of the primary assessment period could be directly used or calculated (ie, trials solely reporting graphical results that would require estimating of scores were excluded). Pharmacotherapies included in the analyses were those appro- ved by the US FDA for the treatment of AR and which, in the opinion of the authors, are commonly currently used and well-studied. The specific pha macotherapies that were included were second-generation oral antihistamines (cetirizine, desloratadine, fexofenadine, levocetirizine, loratadine), intranasal antihistamines (azelastine, olopatadine), oral leukotriene receptor antagonists (montelukast), INCS (aqueous or aerosol beclomethasone dipropionate, budesonide, ciclesonide, fluticasone $\mathrm{p}$ opionate, fluticasone fu oate, mometasone furoate, triamcinolone acetonide), combination intranasal antihistamines/INCS (azelastine/flu ticasone), and combination oral antihistamines/decongestants (cetirizine/pseudoephedrine, desloratadine/pseudoephedrine, fexofenadine/pseudoephedrine, loratadine/pseudoephedrine). Trials evaluating only firs -generation antihistamines were excluded because of limited availability of published randomized, double-blind placebo-controlled trials and because they are no longer recommended as firs -line therapy due to their side effect profil . SLIT-tablet trials were limited to those evaluating products approved by the FDA for the treatment of AR, which at the writing of this analysis limits the products to those for grass (Grastek ${ }^{\circledast}$, Oralair $\left.{ }^{\circledast}\right)$, ragweed (Ragwitek ${ }^{\circledast}$ ), and house dust mite (Odactra' ${ }^{\mathrm{TM}}$ ) allergies.

\section{Systematic searches and data collection process}

PubMED/MEDLINE and EMBASE databases were searched for relevant trials. Searches were limited up to July 18, 2019 and English-only publications. EMBASE searches were limited to May 18, 2016 through May 18, 2018. The search strings used are defined in the Suppleme tal Material.

Records identified du ing the database searches were initially reviewed in duplicate by EPS and an independent reviewer for inclusion based on the specified c iteria using the title and abstract. In the case of discrepancies, a third reviewer provided resolution. Full texts of the initially identified po ential articles were then reviewed by EPS and an independent reviewer for determination of final $t$ ial inclusion and data extraction.

Data from identified $t$ ials that met all the inclusion criteria were entered into an Excel spreadsheet by EPS. HSF conducted quality checks of the data extraction. The primary data elements extracted from the articles and used as inputs in the meta-analyses were the placebo and active treatment(s) TNSS at the end of the primary assessment period, along with the corresponding sample sizes and other trial information. TNSS could have been scored on any scale and include any number of symptoms. In cases where symptom scores were reported as instantaneous and refle tive, or as 12 hour and 24 hours, whichever measurement was defined in the $t$ ial as the primary endpoint was the measurement captured. Where multiple time points were assessed, the time point defined or the primary endpoint was captured. In situations where multiple doses were evaluated, the dose that was FDA-approved and which showed the greatest effic y was 

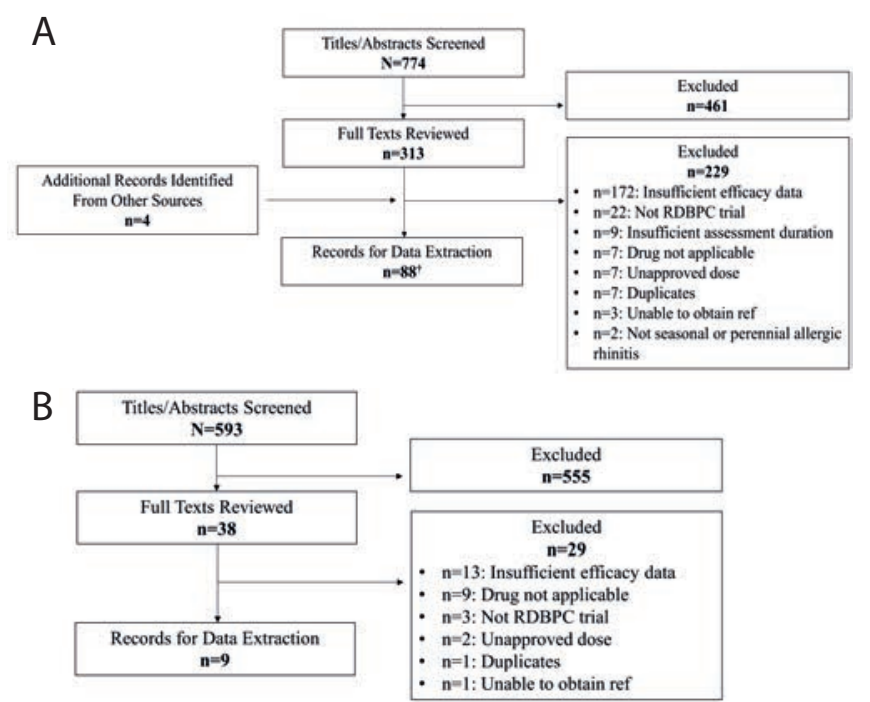

Figure 1. Trial selection for A) pharmacotherapies and B) sublingual immunotherapy (SLIT)-tablets. ${ }^{\dagger} 12$ trials evaluated more than one medication included in the analysis. RDBPC, randomised, double-blind placebo-controlled.

the dose used for the meta-analyses.

\section{Risk of bias and heterogeneity assessment}

Potential biases in the individual studies were assessed by the Cochrane Risk of Bias tool by EPS ${ }^{(11)}$. Modific tions and definiti ons for subjective assessment of the bias domains (ie, attrition bias, etc.) were followed as described by Liu et al. ${ }^{(12)}$. Bias in each category was assigned as "low", "probably no", or "probably yes". Publication biases across trials for each treatment class were assessed visually by funnel plots and statistically by Egger's test. Heterogeneity among the pooled trials was assessed by $I^{2}$ and the Cochran's Q-test. Additional details for assessment of publication bias and heterogeneity are described in the Supplemental Material.

\section{Data synthesis}

Trials were categorized into assessment of therapy for adult/ adolescent SAR, adult/adolescent PAR, pediatric SAR, and pediatric PAR groups. Adult/adolescent trials were defined as those that included subjects aged 12 years and older. In the few trials that included both children and adults, the results were analyzed in the adult/adolescent group. The main outcome evaluated in each meta-analysis was the mean numerical difference in average daily sum TNSS between placebo and active treatment at the end of the primary assessment period. Particularly in the pharmacotherapy trials, TNSS was often reported as change from baseline, in which case the final s ore at the end of the assessment period was calculated using baseline data. All TNSS data were converted to refle $t$ the average daily sum on a scale of 0 to 12 . When trials reported TNSS scores that could not be converted to the 0 to 12 scale, there was an attempt to obtain usable data from the corresponding authors. If usable data were not obtained, the trial was excluded. When standard deviations were not reported, a hierarchy of methods for imputation was used in line with published best practices (see Supplemental Material).

Meta-analyses were conducted using fi ed effects and random effects modeling. The overall effect size and corresponding 95\% Cl for each of the pharmacotherapy classes and SLIT-tablets in the adult/adolescent SAR, adult/adolescent PAR, pediatric SAR, and pediatric PAR categories were calculated. Heterogeneity tests indicated significa theterogeneity among the trials within the treatment classes. Thus, only the results of the random effects modeling are reported. Random-effects meta-analyses estimated the mean difference for each medication group weighted by the inverse of the trial variance. Cook's test was conducted to identify trials that heavily influen ed the analysis results. Sensitivity analyses removing the heavy-influencing trials did not notably alter the effect sizes. Meta-analyses were performed using R Studio Version 1.0.136 and the Metafor package version 1.9-7.

AIT trials allow the use of rescue symptom-relieving pharmacotherapy in both active and placebo groups, which leads to lower symptoms scores in placebo than would be expected with a true placebo. To address this issue, reporting the impact on symptoms (with or without medication scores) as the percentage improvement relative to placebo is advocated by professional allergy societies and AIT experts ${ }^{(13,14)}$. In an effort to put the results into a context that more closely matches typical SLIT-tablet trial reporting, the percentage relative improvement versus placebo was calculated for each treatment class by dividing the meta-analytic weighted treatment difference by the placebo TNSS ([active treatment-placebo]/placebo) x 100\%).

\section{Results}

From the pharmacotherapy searches, 774 records were screened and 461 records were excluded before full-text review. Of the 313 full-texts reviewed, 88 records were ultimately used for data extraction (Figure 1A). For the SLIT-tablet searches, 593 records were screened and 555 records were excluded before full-text review. Of the 38 full-texts reviewed, 9 records were used for data extraction (Figure 1B). The primary reason for record exclusion in all therapy classes was insuffici t reporting of usable TNSS data. The greatest number of eligible trials were in the INCS medication class (Table 1). Characteristics of the trials used in the meta-analysis are shown in Supplemental Tables E2- E5.

\section{Treatment effects for adult/adolescent SAR}

All treatment classes demonstrated a significa $t$ improvement in nasal symptoms associated with adult/adolescent SAR vs placebo (Table 1). Forest plots for each medication class show that 
Table 1. Treatment effects of pharmacotherapies and allergy immunotherapies for adult/adolescent SAR, adult/adolescent PAR, pediatric SAR, and pediatric PAR.

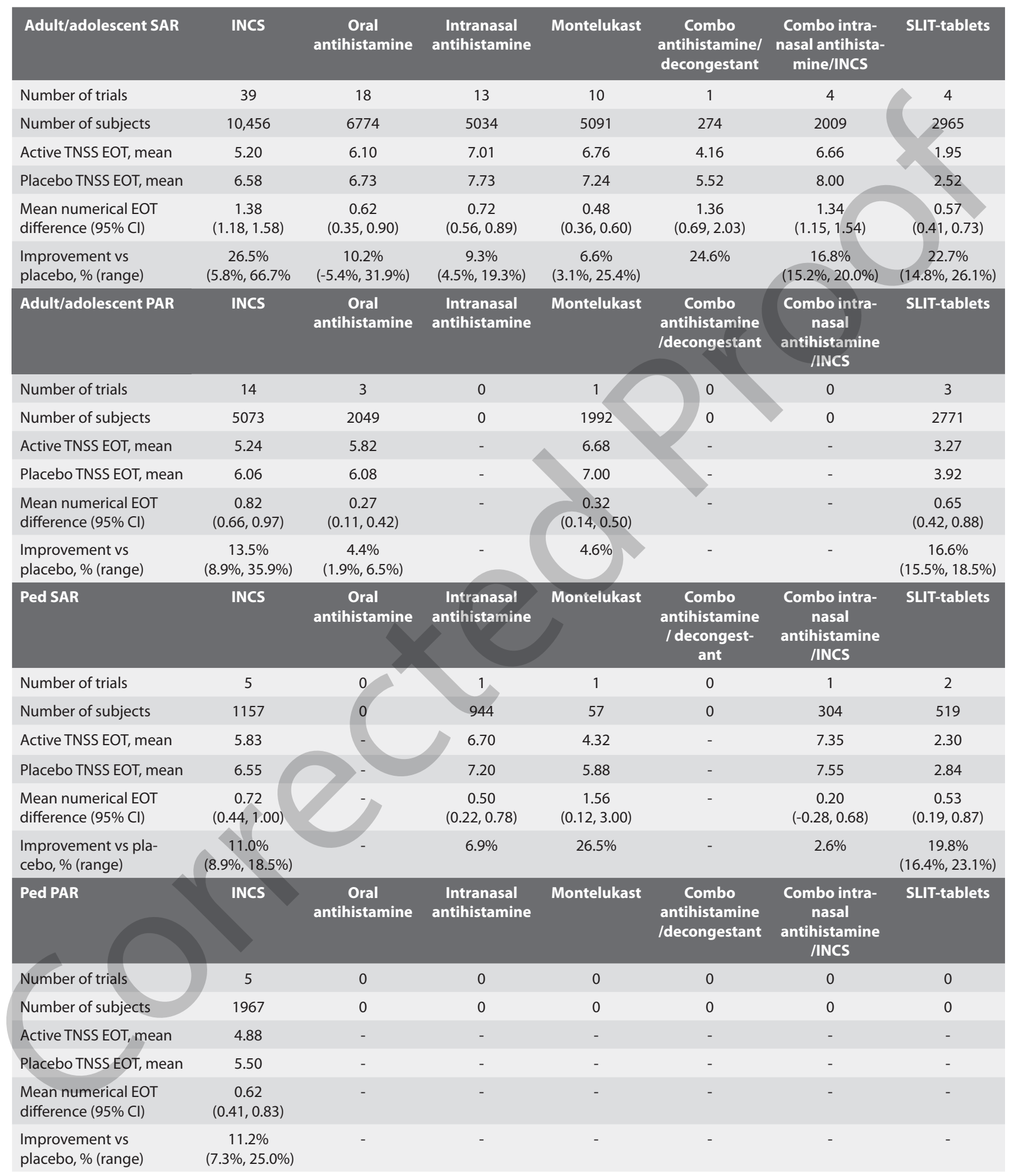

EOT, end of treatment; INCS, intranasal corticosteroids; PAR, perennial allergic rhinitis; SAR, seasonal allergic rhinitis; SLIT, sublingual immunotherapy; TNSS, total nasal symptom score. 


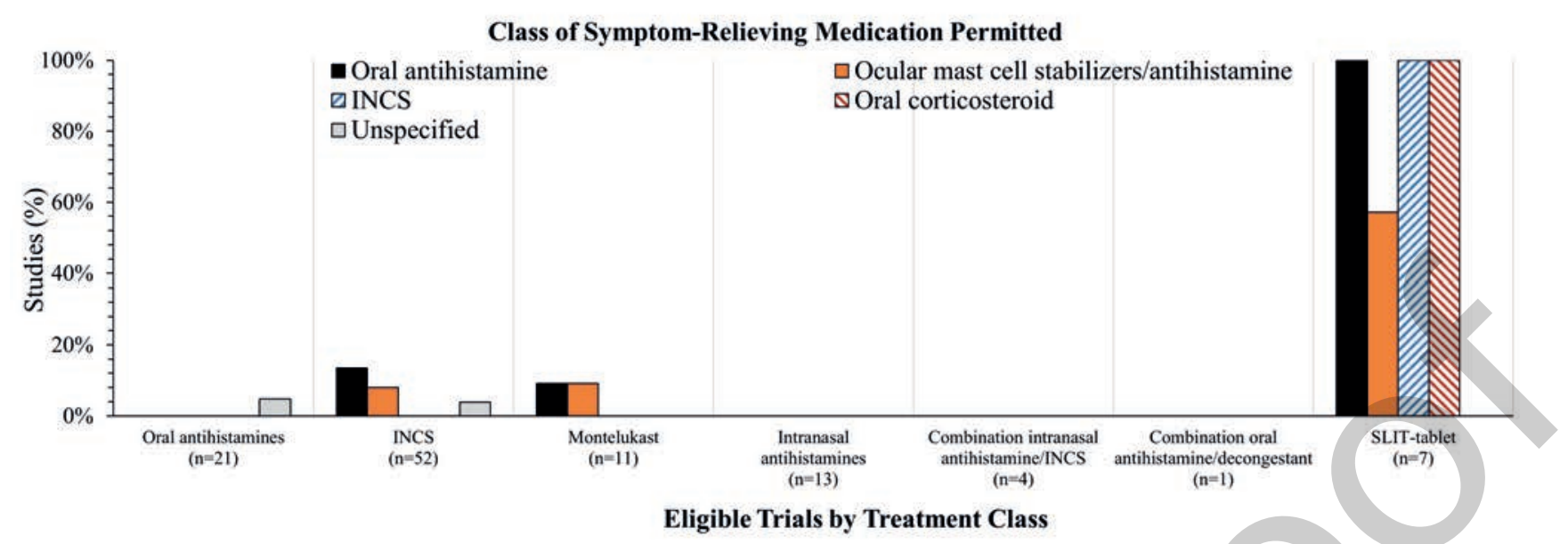

Figure 2. Proportion of all eligible trials (adult/adolescent and pediatric) addressing seasonal and perennial allergic rhinitis with trial designs permitting the use of symptom-relieving medication. Allowed use of symptom-relieving medication was undocumented in 19 of the pharmacotherapy trials.

most individual trials demonstrated a significa $t$ improvement in TNSS with active treatment versus placebo (see Supplemental Figures E1A-F) ${ }^{(15-79)}$. The mean difference in TNSS versus placebo $(95 \% \mathrm{Cl})$ in the analyzed medication classes was: INCS $=1.38$ $(1.18,1.58)$; combination intranasal antihistamine/INCS $=1.34$ $(1.15,1.54)$; intranasal antihistamines $=0.72(0.56,0.89)$; oral antihistamines $=0.62(0.35,0.90)$; SLIT-tablets $=0.57(0.41,0.73)$; and montelukast $=0.48(0.36,0.60)$. Although excluded from the meta-analysis, in the one eligible trial for combination oral antihistamine/decongestant, the mean difference $(95 \% \mathrm{CI})$ in TNSS versus placebo was $1.36(0.69,2.03)^{(80)}$.

Rescue symptom-relieving pharmacotherapy use was allowed in active and placebo groups in 8 of the 72 pharmacotherapy trials for adult SAR that reported this information (undocumented in 13 pharmacotherapy trials) and all of the SLIT-tablet trials (Supplemental Tables E2 and E4).

\section{Treatment effects for adult/adolescent PAR}

All treatment classes demonstrated a significa $t$ improvement in nasal symptoms associated with adult/adolescent PAR vs placebo (Table 1). The treatment effect of the pharmacotherapies on nasal symptoms appears to be less for adult/adolescent PAR compared with SAR (Table 1). Forest plots for each medication class show that most individual trials demonstrated a significa $t$ improvement in TNSS with active treatment versus placebo (see Supplemental Figures E2A-C) ${ }^{(81-103)}$. The mean difference in TNSS versus placebo $(95 \% \mathrm{Cl})$ was: INCS $=0.82(0.66,0.97 ; 14$ trials); SLIT-tablets $=0.65(0.42,0.88 ; 3$ trials); and oral antihistamines $=0.27(0.11,0.42 ; 3$ trials $)$. Although excluded from the meta-analysis, in the one eligible trial for montelukast, the mean difference $(95 \% \mathrm{Cl})$ in TNSS versus placebo was $0.32(0.14,0.50)$ ${ }^{(104)}$. There were no eligible trials of intranasal antihistamines, combination intranasal antihistamines/INCS, or combination oral antihistamine/decongestant identified or adult/adolescent PAR.

Rescue symptom-relieving pharmacotherapy use was allowed in active and placebo groups in 3 of the 14 pharmacotherapy trials for adult/adolescent PAR that reported this information (undocumented in 4 pharmacotherapy trials) and all of the SLIT-tablet trials (Supplemental Tables E2 and E4).

\section{Treatment effects for pediatric SAR and PAR}

The number of pediatric SAR and PAR trials eligible for metaanalyses was limited. For pediatric SAR there were 5 INCS trials and 2 SLIT-tablet trials identified Table 1) ${ }^{(105-111)}$. Three of the 5 INCS trials had $95 \% \mathrm{Cl}$ for the mean difference that crossed zero, indicating the treatment difference was not significa $t$ from placebo (Supplemental Figure E3A). Forest plots for the 2 pediatric SAR SLIT-tablet trials show that both trials demonstrated a significa $t$ improvement in TNSS with active treatment versus placebo (Supplemental Figure E3B). The overall mean difference in TNSS versus placebo $(95 \% \mathrm{Cl})$ for INCS was $0.72(0.44,1.00)$ and for SLIT-tablets was $0.53(0.19,0.87)$. The mean differences $(95 \% \mathrm{Cl})$ in TNSS versus placebo in the one eligible trial each for intranasal antihistamine and combination intranasal antihistamine/INCS for pediatric SAR were $0.50(0.22,0.78)$ and 0.20 $(-0.28,0.68)$, respectively ${ }^{(112,113)}$. For the one identified eli ible trial of montelukast for pediatric SAR ${ }^{(14)}$, the small sample size $(n=57)$, unusually low placebo effect, and large $95 \% \mathrm{Cl}$ makes the TNSS mean difference of $1.56(95 \% \mathrm{Cl}, 0.12,3.00)$ very questionable, especially when compared with the findings in all other montelukast studies as reported above.

For pediatric PAR, the only eligible trials identified ere 5 INCS trials (Table 1$)^{(115-119)}$. Two of these 5 INCS trials had $95 \% \mathrm{Cl}$ for 
the mean difference that crossed zero, indicating the treatment difference was not significa $t$ from placebo (Supplemental Figure E3C). However, the overall mean difference in TNSS versus placebo $(95 \% \mathrm{Cl})$ for INCS was $0.62(0.41,0.83)$.

Symptom-relieving pharmacotherapy use was allowed in active and placebo groups in 3 of the 7 pharmacotherapy pediatric SAR trials and 3 of the 4 pediatric PAR trials that reported this information (undocumented in 1 pharmacotherapy pediatric SAR trial and 1 pediatric PAR trial) (Supplemental Tables E3 and E5). Symptom-relieving pharmacotherapy use was allowed in active and placebo groups in both of the SLIT-tablet pediatric SAR trials.

\section{Percentage relative improvement versus placebo}

Using the percentage relative improvement in TNSS versus placebo resulted in a different pattern of effic $y$ ranking than the pattern observed when comparing mean numerical differences (Table 1). SLIT-tablets demonstrated a similar percentage improvement to that of INCS. Pharmacotherapies assessed by differences in percentage improvement again appear to have less of a treatment effect in adult/adolescent PAR compared with adult/ adolescent SAR (Table 1).

\section{Bias and heterogeneity assessment}

Selection and performance bias were considered "probably yes" for a large number of the trials. This potential bias was primarily due to lack of reporting for specific andomization and blinding procedures.

There was considerable heterogeneity among trials in disease severity, trial duration, and symptom-relieving medication use (Figure 2). Based on the $\mathrm{I}^{2}$ value and Q-tests, the INCS and oral antihistamine adult/adolescent SAR trials exhibited significa $t$ and high heterogeneity; intranasal antihistamine adult/adolescent SAR trials exhibited significa $t$ and medium heterogeneity. Because of the limited sample size, it is likely that the Q-tests were underpowered for most of the other analyses.

A significa t publication bias based on the Egger's test was noted for the INCS and intranasal antihistamine adult/adolescent SAR trials and for the INCS adult/adolescent PAR trials. Funnel plots for INCS and oral antihistamines in adult/adolescent trials indicate a strong tendency toward publication of trials with positive outcomes (see Supplemental Figures E4A-D). As with the heterogeneity tests, the Egger's test was likely underpowered for most of the other analyses that had small sample sizes ( $<10$ trials).

\section{Discussion}

These meta-analyses were conducted to systematically evaluate the effic $y$ of pharmacotherapy and SLIT-tablets versus placebo in the treatment of adult/adolescent and pediatric SAR and PAR, using the most widely reported endpoint, the TNSS (a score based on self-reported nasal symptoms). Despite extensive, careful analyses, the results were not suffici $t$ to make defi nitive comparative effic $y$ conclusions among AR treatment classes, emphasizing the need for direct head-to-head trials. In general, all the treatment classes analyzed resulted in a signifi cant improvement in nasal symptoms versus placebo for adult/ adolescent SAR and adult/adolescent PAR. The largest improvement in TNSS for any pharmacotherapy was observed with INCS used alone or in combination with intranasal antihistamines. SLIT-tablets also provided clinically meaningful improvements in TNSS despite concomitant rescue symptom-relieving medication use, which was permitted in all SLIT-tablet trials. Although this is the first meta-anal ses that has attempted to compare AR pharmacotherapies for SAR and PAR in both adult/adolescent and pediatric populations, the number of eligible trials limited the ability to conduct meta-analyses for pediatric SAR and PAR. Two other meta-analyses have previously compared pharmacotherapies and SLIT-tablets for SAR, but these previous metaanalyses had some limitations. A meta-analysis by Devillier et al. (8), examined effect sizes with INCS, oral antihistamines, montelukast, and combination intranasal antihistamine/INCS and grass SLIT-tablets, for SAR, but did not make a distinction in their analysis between total symptom scores that contained ocular symptoms and total nasal symptom scores. A meta-analysis by Durham et al. (9), examined TNSS effect sizes with INCS, oral antihistamine, and montelukast and SLIT-tablets for adult SAR and PAR, but the analyzed trials were limited to a single manufacturer and one specific ormulation within each pharmacotherapy class (e.g., mometasone furoate and desloratadine). Neither of the previous meta-analyses evaluated the treatment effect on children specificall .

TNSS was selected as the primary endpoint for these metaanalyses although the TNSS for AR trials has never been standardized or validated. Nevertheless, TNSS is the endpoint recommended by the FDA and other regulatory agencies for AR trials and an initial feasibility review revealed that TNSS was the most commonly reported primary endpoint in pharmacotherapy trials. The TNSS was also available in many of the SLIT-tablet trials. In the SLIT-tablet trials, the TNSS was most often reported as an individual component of the combined symptom and medication score. The combined symptom and medication score is considered a more recent and clinically meaningful endpoint from the perspective of the FDA and other regulatory agencies and is the most commonly reported endpoint in SLIT-tablet trials. However, it is not an endpoint that is used in pharmacotherapy trials, thus, TNSS was chosen as the best outcome for these meta-analyses. A major limitation of these meta-analyses was the number of trials ineligible for inclusion because of insuffici t TNSS reporting. To be eligible for the meta-analyses, the TNSS had to be reported in such a way that actual scores at the end of the primary assessment period could be directly 
used or calculated, not simply in a graph without numeric labels or values in the text. The largest number of eligible trials for the meta-analyses were for adult/adolescent SAR. The lack of eligible trials made meta-analyses among treatment classes underpowered for adult/adolescent PAR, and few analyses were able to be conducted for pediatric SAR and PAR. Comparisons of treatment effects across a small number of trials may be impacted by low power, and the conclusions drawn from these comparisons may be subject to misinterpretation.

Most of the pharmacotherapy trials eligible for the current metaanalyses reported TNSS as a change from baseline. Because of the nature of SLIT-tablet trial design, baseline TNSS was not available for seasonal SLIT-tablet trials. Therefore, TNSS at end of assessment was the only feasible time point. The pharmacotherapy trials that only reported a change from baseline required a calculation using baseline values to convert to the primary measure of TNSS at end of assessment. Thus, a "basement effect" may also impact comparisons versus placebo among the treatment classes. This is best illustrated in the results for the combination intranasal antihistamine/INCS trials versus the INCS trials. The percentage improvement relative to placebo was only $16.8 \%$ with combination treatment compared with $26.5 \%$ for INCS alone. This result is contrary to what is expected since the individual combination treatment trials showed a significa tly better effect on TNSS symptoms versus INCS monotherapy controls ${ }^{(46,47)}$. The average baseline TNSS scores in the combination treatment were approximately 1.5 points (out of max of 12) higher than the average baseline in the INCS trials. As a theoretical exercise, when the end of treatment TNSS scores for the combination trials were recalculated using the average baseline scores from the INCS trials, the percentage improvement with combination treatment increased to $22 \%$, indicating a basement effect. On the other hand, low placebo TNSS scores, as seen in the SLIT-tablet trials, create a "ceiling effect" in which there is little room to demonstrate improvement.

The substantial difference in the permitted use of rescue symptom-relieving medication between pharmacotherapy and SLITtablet trials for subjects receiving active treatment or placebo is one of the largest potential sources of confounding when comparing SLIT-tablet treatment effects versus pharmacotherapy. As a result of rescue symptom-relieving medication use, reported symptom responses in both active and placebo groups may be lower, masking differences between the groups. To address this issue, SLIT-tablet trials usually report the impact on symptoms (with or without medication scores) as the percentage improvement relative to placebo (aka, the relative clinical impact $[\mathrm{RCI}]$ ). When using the percentage improvement relative to placebo in the current meta-analyses, the pattern of effic $y$ for adult/adolescent SAR changed from the pattern observed with the mean numerical difference. This may explain the confli ting results for the effect of SLIT-tablets for adult/adolescent SAR, which is no- tably lower than INCS based on mean numerical difference $(0.57$ vs 1.38 ) but is comparable with INCS when based on percentage change relative to placebo $(22.7 \%$ vs $26.5 \%)$.

Significa theterogeneity was detected for the INCS, oral antihistamine, and intranasal antihistamine adult/adolescent SAR trials. Heterogeneity between pharmacotherapy and SLIT-tablet trials in regards to trial duration, population disease severity, and allowed rescue symptom-relieving medication use was acknowledged in both the previous meta-analyses ${ }^{(8,9)}$. Some of the heterogeneity among trials in the current analyses could potentially have been addressed by conducting subgroup analyses of trials with similar trial durations or that treated the same allergen, etc. However, the overall small numbers of eligible identified $t$ ials for most of the treatment classes would preclude any meaningful analysis for most subgroups.

Publication bias is a well-known confounder and can lead to overestimation of a drug's effic y. Funnel plots indicated significa t publication bias towards trials with positive outcomes for INCS and oral antihistamines in adults/adolescents but were underpowered for those analyses that had less than 10 trials. Lastly, these analyses were limited to pharmacotherapies approved and available in the US. Other pharmacotherapies are available in other countries. A meta-analysis of SCIT trials compared with pharmacotherapy would be of interest, however, there is substantial heterogeneity among the SCIT trials and most are relatively small ( $<150$ patients total) compared with the large populations evaluated in the SLIT-tablet trials. Thus, meta-analyses of SCIT trials compared with pharmacotherapy would have even more limitations than the current analyses; the current analyses were therefore limited to SLIT-tablets.

\section{Conclusion}

In summary, all treatments significa tly improved nasal symptoms versus placebo for adult/adolescent SAR and adult/ adolescent PAR. Analyses of treatments for pediatric SAR and PAR were limited by the small number of eligible trials and additional well controlled trials in this population are needed. Major limitations including, but not limited to, high heterogeneity within each treatment class, differential use of rescue symptomrelieving medication between treatment classes, and strong evidence of publication bias do not permit indirect comparisons among treatment classes. The value of future meta-analyses comparing effects of different treatments for SAR and PAR are questionable in the absence of well-designed head-to-head trials. The lack of comparative effic y information among treatment classes emphasizes the importance of shared decision making in the management of AR.

\section{Acknowledgements}

Medical writing and editorial assistance were provided by Erin $\mathrm{P}$. Scott, PhD, of Scott Medical Communications, LLC. This assis- 
tance was supported by ALK-Abelló, Hørsholm, Denmark.

\section{Authorship contribution}

All authors contributed to the development of the selection criteria, search strategy, and outcomes assessment. EPS designed and conducted the searches and data extraction and wrote the first $d$ aft of the manuscript. EOM, DW, and HN provided clinical expertise. PN and HF provided statistical expertise and conducted the statistical analyses. All authors provided critical review of the manuscript and approved for submission for publication.

\section{Conflict of interest}

E.O. Meltzer has served as a consultant or speaker for ALKAbelló, AstraZeneca, Boehringer Ingelheim, GlaxoSmithKline, GossamerBio, Merck, Mylan, Optinose and Sanofi/ egeneron. D.
Wallace has served as consultant or speaker for ALK-Abelló, Sanofi/ egeneron, OpiNose, Mylan, and Kaleo. H.S. Friedman and P. Navaratnam are employees of DataMed Solutions, LLC, which provides consulting services to ALK-Abelló, Hørsholm, Denmark. E.P. Scott is an employee of Scott Medical Communications, LLC, which provides medical writing services to ALK-Abelló, Hørsholm, Denmark. H. Nolte is an employee of ALK-Abelló.

\section{Financial disclosure}

These meta-analyses were funded by ALK-Abelló, Hørsholm, Denmark. The sponsor (ALK-Abelló) provided clinical expertise in the development of the protocol, interpretation of the data, and was involved in development of the report. All authors agreed to submission of the report for publication.

\section{References}

1. Bousquet PJ, Demoly P, Devillier P, Mesbah $\mathrm{K}$, Bousquet J. Impact of allergic rhinitis symptoms on quality of life in primary care. Int Arch Allergy Immunol. 2013; 160: 393400.

2. Meltzer EO, Farrar JR, Sennett C. Findings from an Online Survey Assessing the Burden and Management of Seasonal Allergic Rhinoconjunctivitis in US Patients. J Allergy Clin Immunol Pract. 2017; 5: 77989 e6.

3. Bielory L, Skoner DP, Blaiss MS, et al. Ocular and nasal allergy symptom burden in America: the Allergies, Immunotherapy, and RhinoconjunctivitiS (AIRS) surveys. Allergy Asthma Proc. 2014; 35: 211-8.

4. Meltzer EO, Nathan R, Derebery J, et al. Sleep, quality of life, and productivity impact of nasal symptoms in the United States: findings from the Burden of Rhinitis in America survey. Allergy Asthma Proc. 2009; 30: 244-54.

5. Bousquet J, Khaltaev N, Cruz AA, et al. Allergic Rhinitis and Its Impact on Asthma (ARIA) 2008 update (in collaboration with the World Health Organization, GA(2)LEN and AllerGen). Allergy. 2008; 63: 8-160

6. Brożek JL, Bousquet J, Agache I, et al. Allergic Rhinitis and its Impact on Asthma (ARIA) guidelines-2016 revision. J Allergy Clin Immunol. 2017; 140: 950-8.

Wise SK, Lin SY, Toskala E, et al. International Consensus Statement on Allergy and Rhinology: Allergic Rhinitis. Int Forum Allergy Rhinol. 2018; 8: 108-352.

8. Devillier P, Dreyfus JF, Demoly P, Calderon MA. A meta-analysis of sublingual allergen immunotherapy and pharmacotherapy in pollen-induced seasonal allergic rhinoconjunctivitis. BMC Med. 2014; 12: 71

9. Durham SR, Creticos PS, Nelson HS et al. Treatment Effect of Sublingual I mmunotherapy Tablets and Pharmacotherapies for Seasonal and Perennial Allergic Rhinitis: Pooled Analyses. J Allergy Clin Immunol. 2016; 138: 1081-8.
10. Moher D, Liberati A, Tetzlaff J, Altman DG, Group P. Preferred reporting items for systematic reviews and meta-analyses: the PRISMA statement. PLoS Med. 2009; 6: e1000097.

11. The Cochrane Collaboration's tool for assessing risk of bias. In: Higgins J, Green Se, editors. Cochrane Handbook for Systematic Reviews of Interventions Version 5102011.

12. Liu G, Zhou X, Chen J, Liu F. Ora Antihistamines Alone vs in Combination with Leukotriene Receptor Antagonists for Allergic Rhinitis: A Meta-analysis. Otolaryngol Head Neck Surg. 2018; 158: 450-8.

13. Bousquet J, Schunemann HJ, Bousquet PJ et al. How to design and evaluate randomized controlled trials in immunotherapy for allergic rhinitis: an ARIA-GA(2) LEN statement. Allergy. 2011; 66: 765-74.

14. Nelson HS, Calderon MA, Bernstein DI, et al. Allergen Immunotherapy Clinical Trial Outcomes and Design: Working Toward Harmonization of Methods and Principles. Curr Allergy Asthma Rep. 2017; 17: 18.

15. Andrews $C P$, Martin $B G$, Jacobs $R L$, et al Fluticasone furoate nasal spray is more effective than fexofenadine for nighttime symptoms of seasonal allergy. Allergy Asthma Proc. 2009; 30: 128-38.

16. Bronsky EA, Aaronson DW, Berkowitz RB, et al. Dose ranging study of mometasone furoate (Nasonex) in seasonal allergic rhinitis. Ann Allergy Asthma Immunol. 1997; 79: 51-6.

17. Bronsky EA, Dockhorn RJ, Meltzer EO, et al. Fluticasone propionate aqueous nasal spray compared with terfenadine tablets in the treatment of seasonal allergic rhinitis. J Allergy Clin Immunol. 1996; 97: 915-21.

18. Creticos P, Fireman P, Settipane G, Bernstein D, Casale T, Schwartz H. Intranasal budesonide aqueous pump spray (Rhinocort Aqua) for the treatment of seasonal allergic rhinitis. Rhinocort Aqua Study Group. Allergy Asthma Proc. 1998; 19: 285-94.

19. Di Lorenzo G, Gervasi F, Drago A, et al.
Comparison of the effects of fluticasone propionate, aqueous nasal spray and levocabastine on inflammatory cells in nasal lavage and clinical activity during the pollen season in seasonal rhinitics. Clin Exp Allergy. 1999; 29: 1367-77.

20. Di Lorenzo G, Pacor ML, Pellitteri ME, et al. Randomized placebo-controlled trial comparing fluticasone aqueous nasal spray in mono-therapy, fluticasone plus cetirizine, fluticasone plus montelukast and cetirizine plus montelukast for seasonal allergic rhinitis. Clin Exp Allergy. 2004; 34: 259-67.

21. Dykewicz MS, Kaiser HB, Nathan RA, et al. Fluticasone propionate aqueous nasal spray improves nasal symptoms of seasonal allergic rhinitis when used as needed (prn). Ann Allergy Asthma Immunol. 2003; 91: 44-8.

22. Findlay S, Huber F, Garcia J, Huang L. Efficacy of once-a-day intranasal administration of triamcinolone acetonide in patients with seasonal allergic rhinitis. Ann Allergy. 1992; 68: 228-32.

23. Fokkens WJ, Jogi R, Reinartz S, et al. Once daily fluticasone furoate nasal spray is effective in seasonal allergic rhinitis caused by grass pollen. Allergy. 2007; 62: 1078-84.

24. Ford LB, Matz J, Hankinson T, Prillaman B, Georges G. A comparison of fluticasone propionate nasal spray and cetirizine in ragweed fall seasonal allergic rhinitis. Allergy Asthma Proc. 2015; 36: 313-9.

25. Graft D, Aaronson D, Chervinsky P, et al. A placebo- and active-controlled randomized trial of prophylactic treatment of seasonal allergic rhinitis with mometasone furoate aqueous nasal spray. J Allergy Clin Immunol. 1996; 98: 724-31.

26. Jacobs R, Martin B, Hampel F, Toler W Ellsworth A, Philpot E. Effectiveness of fluticasone furoate 110 microg once daily in the treatment of nasal and ocular symptoms of seasonal allergic rhinitis in adults and adolescents sensitized to mountain cedar pollen. Curr Med Res Opin. 2009; 25: 1393-401.

27. Kaiser HB, Naclerio RM, Given J, Toler TN, Ellsworth A, Philpot EE. Fluticasone furoate 
nasal spray: a single treatment option for the symptoms of seasonal allergic rhinitis. J Allergy Clin Immunol. 2007; 119: 1430-7.

28. Mansfield LE, Posey CR. Daytime sleepiness and cognitive performance improve in seasonal allergic rhinitis treated with intranasal fluticasone propionate. Allergy Asthma Proc. 2007; 28: 226-9.

29. Martin BG, Ratner PH, Hampel FC, et al Optimal dose selection of fluticasone furoate nasal spray for the treatment of seasonal allergic rhinitis in adults and adolescents. Allergy Asthma Proc. 2007; 28: 216-25.

30. Meltzer EO, Jalowayski AA, Orgel HA, Harris AG. Subjective and objective assessments in patients with seasonal allergic rhinitis: effects of therapy with mometasone furoate nasal spray. J Allergy Clin Immunol. 1998; 102: 39-49.

31. Meltzer EO, Shekar T, Teper AA Mometasone furoate nasal spray for moderate-to-severe nasal congestion in subjects with seasonal allergic rhinitis. Allergy Asthma Proc. 2011; 32: 159-67.

32. Munk ZM, Gross GN, Hampel FC, Jr., Ratner $\mathrm{PH}$. Preseasonal, once daily triamcinolone acetonide nasal aerosol for seasonal allergic rhinitis. Ann Allergy Asthma Immunol. 1997; 78: 325-31.

33. Munk ZM, LaForce C, Furst JA, Simpson B, Feiss G, Smith JA. Efficacy and safety of triamcinolone acetonide aqueous nasal spray in patients with seasonal allergic rhinitis. Ann Allergy Asthma Immunol. 1996; 77: 277-81.

34. Okubo K, Nakashima M, Miyake N, Komatsubara M, Okuda M. Comparison of fluticasone furoate and fluticasone propionate for the treatment of Japanese cedar pollinosis. Allergy Asthma Proc. 2009; 30: 84-94.

35. Prenner BM, Lanier BQ, Bernstein DI, Shekar T, Teper A. Mometasone furoate nasal spray reduces the ocular symptoms of seasonal allergic rhinitis. J Allergy Clin Immunol. 2010; 125: 1247-53.e5.

36. Raphael GD, Berger WE, Prenner BM, Finn $A F$, Jr., Kelley L, Tantry SK. Efficacy, safety, and optimal dose selection of beclomethasone dipropionate nasal aerosol for seasonal allergic rhinitis in adolescents and adults. Curr Med Res Opin. 2013; 29: 1329-40.

37. Ratner PH, van Bavel JH, Martin BG, et al. A comparison of the efficacy of fluticasone propionate aqueous nasal spray and loratadine, alone and in combination, for the treatment of seasonal allergic rhinitis. J Fam Pract. 1998; 47: 118-25.

38. Ratner $\mathrm{PH}$, Wingertzahn MA, van Bavel JH, Hampel F, Darken PF, Shah T. Efficacy and safety of ciclesonide nasal spray for the treatment of seasonal allergic rhinitis. J Allergy Clin Immunol. 2006; 118: 1142-8.

39. Rosenthal R, Berger W, Bronsky E, et al. TriNasal triamcinolone acetonide nasal spray 200 and 400 micrograms qd versus placebo and Nasacort triamcinolone acetonide nasal aerosol 440 micrograms qd in patients suffering from seasonal allergic rhinitis dur- ing the grass season. Am J Rhinol. 1998; 12: 427-33.

40. Schenkel E, Newman KB. Therapeutic equivalence of triamcinolone acetonide hydrofluoroalkane and chlorofluorocarbon nasal inhalers in patients with seasonal allergic rhinitis. Am J Rhinol Allergy. 2013; 27: 10912.

41. Steensen $H$, Lindqvist N. Treatment of grass pollen-induced hay fever with intranasal budesonide. A double-blind clinical comparison between budesonide and placebo. Allergy. 1981; 36: 245-9.

42. Stern MA, Dahl R, Nielsen LP, Pedersen B, Schrewelius C. A comparison of aqueous suspensions of budesonide nasal spray (128 micrograms and 256 micrograms once daily) and fluticasone propionate nasal spray (200 micrograms once daily) in the treatment of adult patients with seasonal allergic rhinitis. Am J Rhinol. 1997; 11: 32330.

43. Tinkelman D, Falliers C, Gross G, et al. Multicenter evaluation of triamcinolone acetonide nasal aerosol in the treatment of adult patients with seasonal allergic rhinitis. Ann Allergy. 1990; 64: 234-40.

44. van Bavel JH, Ratner PH, Amar NJ, et al. Efficacy and safety of once-daily treatment with beclomethasone dipropionate nasal aerosol in subjects with seasonal allergic rhinitis. Allergy Asthma Proc. 2012; 33: 38696.

45. Anolik R. Clinical benefits of combination treatment with mometasone furoate nasal spray and loratadine vs monotherapy with mometasone furoate in the treatment of seasonal allergic rhinitis. Ann Allergy Asthma Immunol. 2008; 100: 264-71.

46. Carr W, Bernstein J, Lieberman P, et al. A novel intranasal therapy of azelastine with fluticasone for the treatment of allergic rhinitis. J Allergy Clin Immunol. 2012; 129: 1282-9.e10.

47. Hampel FC, Ratner PH, Van Bavel J, et al. Double-blind, placebo-controlled study of azelastine and fluticasone in a single nasal spray delivery device. Ann Allergy Asthma Immunol. 2010; 105: 168-73.

48. Pullerits T, Praks L, Ristioja V, Lotvall J. Comparison of a nasal glucocorticoid, antileukotriene, and a combination of antileukotriene and antihistamine in the treatment of seasonal allergic rhinitis. J Allergy Clin Immunol. 2002; 109: 949-55.

49. Berger WE, White MV. Efficacy of azelastine nasal spray in patients with an unsatisfactory response to loratadine. Ann Allergy Asthma Immunol. 2003; 91: 205-11.

50. Demoly P, Dreyfus I, Dhivert-Donnadieu H, Mesbah K. Desloratadine for the treatment of cypress pollen-induced allergic rhinitis. Ann Allergy Asthma Immunol. 2009; 103: 260-6.

51. Dockhorn RJ, Bergner A, Connell JT, et al. Safety and efficacy of loratadine (Sch29851): a new non-sedating antihistamine in seasonal allergic rhinitis. Ann Allergy.
1987: 58: 407-11.

52. Hampel F, Jr., Howland W, 3rd, Van Bavel J, Ratner P. A randomized, double-blind, placebo-controlled study comparing the efficacy and safety of ebastine $(20 \mathrm{mg}$ and $10 \mathrm{mg}$ ) to loratadine $10 \mathrm{mg}$ once daily in the treatment of seasonal allergic rhinitis. J Investig Allergol Clin Immunol. 2004; 14: 56-63.

53. Kuna P, Bachert C, Nowacki Z, et al. Efficacy and safety of bilastine $20 \mathrm{mg}$ compared with cetirizine $10 \mathrm{mg}$ and placebo for the symptomatic treatment of seasonal allergic rhinitis: a randomized, double-blind, parallel-group study. Clin Exp Allergy. 2009; 39: 1338-47.

54. Lu S, Malice MP, Dass SB, Reiss TF. Clinical studies of combination montelukast and loratadine in patients with seasonal allergic rhinitis. J Asthma. 2009; 46: 878-83.

55. Meltzer EO, Malmstrom K, Lu S, et al. Concomitant montelukast and loratadine as treatment for seasonal allergic rhinitis: a randomized, placebo-controlled clinical trial. J Allergy Clin Immunol. 2000; 105: 91722.

56. Pradalier A, Neukirch C, Dreyfus I, Devillier P. Desloratadine improves quality of life and symptom severity in patients with allergic rhinitis. Allergy. 2007; 62: 1331-4

57. Skassa-Brociek W, Bousquet J, Montes F, et al. Double-blind placebo-controlled study of loratadine, mequitazine, and placebo in the symptomatic treatment of seasonal allergic rhinitis. J Allergy Clin Immunol. 1988; 81: 725-30.

58. Nayak AS, Philip G, Lu S, Malice MP, Reiss TF. Efficacy and tolerability of montelukast alone or in combination with loratadine in seasonal allergic rhinitis: a multicenter, randomized, double-blind, placebo-controlled trial performed in the fall. Ann Allergy Asthma Immunol. 2002; 88: 592-600.

59. Philip G, Malmstrom K, Hampel FC, et al. Montelukast for treating seasonal allergic rhinitis: a randomized, double-blind, placebo-controlled trial performed in the spring. Clin Exp Allergy. 2002; 32: 1020-8.

60. van Adelsberg J, Philip G, LaForce CF, et al. Randomized controlled trial evaluating the clinical benefit of montelukast for treating spring seasonal allergic rhinitis. Ann Allergy Asthma Immunol. 2003; 90: 214-22.

61. Bernstein JA, Prenner B, Ferguson BJ, Portnoy J, Wheeler WJ, Sacks HJ. Doubleblind, placebo-controlled trial of reformulated azelastine nasal spray in patients with seasonal allergic rhinitis. Am J Rhinol Allergy. 2009; 23: 512-7.

62. Howland WC, Amar NJ, Wheeler W, Sacks H. Efficacy and safety of azelastine $0.15 \%$ nasal spray administered once daily in patients with allergy to Texas mountain cedar pollen. Int Forum Allergy Rhinol. 2011; 1: 275-9.

63. LaForce CF, Corren J, Wheeler WJ, Berger WE. Efficacy of azelastine nasal spray in seasonal allergic rhinitis patients who remain symptomatic after treatment with fexofena- 
dine. Ann Allergy Asthma Immunol. 2004 93: 154-9.

64. Lumry W, Prenner B, Corren J, Wheeler W. Efficacy and safety of azelastine nasal spray at a dose of 1 spray per nostril twice daily. Ann Allergy Asthma Immunol. 2007; 99: 267-72.

65. Shah S, Berger W, Lumry W, La Force C, Wheeler W, Sacks H. Efficacy and safety of azelastine $0.15 \%$ nasal spray and azelastine $0.10 \%$ nasal spray in patients with seasonal allergic rhinitis. Allergy Asthma Proc. 2009; 30: 628-33.

66. Shah SR, Nayak A, Ratner P, Roland P, Michael Wall G. Effects of olopatadine hydrochloride nasal spray $0.6 \%$ in the treatment of seasonal allergic rhinitis: a phase III, multicenter, randomized, double-blind, active- and placebo-controlled study in adolescents and adults. Clin Ther. 2009; 31: 99-107.

67. van Bavel J, Howland WC, Amar NJ, Wheeler W, Sacks H. Efficacy and safety of azelastine $0.15 \%$ nasal spray administered once daily in subjects with seasonal allergic rhinitis. Allergy Asthma Proc. 2009; 30: 512-8.

68. Okubo K, Baba K. Therapeutic effect of montelukast, a cysteinyl leukotriene receptor 1 antagonist, on Japanese patients with seasonal allergic rhinitis. Allergol Int. 2008; 57: 247-55

69. Philip G, Nayak AS, Berger WE, et al. The effect of montelukast on rhinitis symptoms in patients with asthma and seasonal allergic rhinitis. Curr Med Res Opin. 2004; 20: 1549-58.

70. van Adelsberg J, Philip G, Pedinoff AJ, et al. Montelukast improves symptoms of seasonal allergic rhinitis over a 4-week treatment period. Allergy. 2003; 58: 1268-76.

71. Charpin D, Gouitaa M, Dron-Gonzalvez M, et al. Immunotherapy with an aluminum hydroxide-adsorbed Juniperus ashei foreign pollen extract in seasonal indigenous cypress pollen rhinoconjunctivitis. A double-blind, placebo-controlled study. Int Arch Allergy Immunol. 2007; 143: 83-91.

72. Ferrer M, Burches E, Pelaez A, et al. Doubleblind, placebo-controlled study of immunotherapy with Parietaria judaica: clinical efficacy and tolerance. J Investig Allergol Clin Immunol. 2005; 15: 283-92.

73. Frew AJ, Powell RJ, Corrigan CJ, Durham SR. Efficacy and safety of specific immunotherapy with SQ allergen extract in treatmentresistant seasonal allergic rhinoconjunctivitis. J Allergy Clin Immunol. 2006; 117: 319-25.

74. Varney VA, Gaga M, Frew AJ, Aber VR, Kay $A B$, Durham SR. Usefulness of immunotherapy in patients with severe summer hay fever uncontrolled by antiallergic drugs. BMJ 1991; 302: 265-9.

75. Zenner HP, Baumgarten C, Rasp G, et al. Short-term immunotherapy: a prospective, randomized, double-blind, placebocontrolled multicenter study of molecular standardized grass and rye allergens in patients with grass pollen-induced allergic rhinitis. J Allergy Clin Immunol. 1997; 100: 23-9.

76. Creticos PS, Maloney J, Bernstein Dl, et al. Randomized controlled trial of a ragweed allergy immunotherapy tablet in North American and European adults. J Allergy Clin Immunol. 2013; 131: 1342-9 e6.

77. Dahl R, Kapp A, Colombo G, et al. Efficacy and safety of sublingual immunotherapy with grass allergen tablets for seasonal allergic rhinoconjunctivitis. J Allergy Clin Immunol. 2006; 118: 434-40.

78. Maloney J, Bernstein DI, Nelson H, et al. Efficacy and safety of grass sublingual immunotherapy tablet, MK-7243: a large randomized controlled trial. Ann Allergy Asthma Immunol. 2014; 112: 146-53.e2.

79. Nelson HS, Nolte H, Creticos P, Maloney J, Wu J, Bernstein DI. Efficacy and safety of timothy grass allergy immunotherapy tablet treatment in North American adults. J Allergy Clin Immunol. 2011; 127: 72-80 e2.

80. Nathan RA, Finn AF, Jr., LaForce C, et al. Comparison of cetirizine-pseudoephedrine and placebo in patients with seasonal allergic rhinitis and concomitant mild-to-moderate asthma: randomized, double-blind study. Ann Allergy Asthma Immunol. 2006; 97: 389-96.

81. Bende M, Carrillo T, Vona I, da Castel-Branco MG, Arheden L. A randomized comparison of the effects of budesonide and mometasone furoate aqueous nasal sprays on nasal peak flow rate and symptoms in perennial allergic rhinitis. Ann Allergy Asthma Immunol. 2002; 88: 617-23.

82. Chervinsky P, Kunjibettu S, Miller DL, et al. Long-term safety and efficacy of intranasal ciclesonide in adult and adolescent patients with perennial allergic rhinitis. Ann Allergy Asthma Immunol. 2007; 99: 69-76.

83. Given JT, Cheema AS, Dreykluft T, et al. Fluticasone furoate nasal spray is effective and well tolerated for perennial allergic rhinitis in adolescents and adults. Am J Rhinol Allergy. 2010; 24: 444-50.

84. Kivisaari E, Baker RC, Price MJ. Comparison of once daily fluticasone propionate aqueous nasal spray with once daily budesonide reservoir powder device in patients with perennial rhinitis. Clin Exp Allergy. 2001; 31: 855-63.

85. Kobayashi RH, Beaucher WN, Koepke JW, et al. Triamcinolone acetonide aqueous nasal spray for the treatment of patients with perennial allergic rhinitis: a multicenter, randomized, double-blind, placebo-controlled study. Clin Ther. 1995; 17: 503-13.

86. Meltzer EO. Clinical and antiinflammatory effects of intranasal budesonide aqueous pump spray in the treatment of perennial allergic rhinitis. Ann Allergy Asthma Immunol. 1998; 81: 128-34.

87. Meltzer EO, Jacobs RL, LaForce CF, Kelley CL, Dunbar SA, Tantry SK. Safety and efficacy of once-daily treatment with beclomethasone dipropionate nasal aerosol in subjects with perennial allergic rhinitis. Allergy Asthma Proc. 2012; 33: 249-57.
88. Meltzer EO, Kunjibettu S, Hall N, et al. Efficacy and safety of ciclesonide, 200 microg once daily, for the treatment of perennial allergic rhinitis. Ann Allergy Asthma Immunol. 2007; 98: 175-81.

89. Mohar D, Berger WE, Laforce C, et al. Efficacy and tolerability study of ciclesonide nasal aerosol in patients with perennial allergic rhinitis. Allergy Asthma Proc. 2012; 33: 19-26.

90. Nathan RA, Berger W, Yang W, et al. Effect of once-daily fluticasone furoate nasal spray on nasal symptoms in adults and adolescents with perennial allergic rhinitis. Ann Allergy Asthma Immunol. 2008; 100: 497505.

91. Spector S, Bronsky E, Chervinsky P, et al. Multicenter, double-blind, placebo-controlled trial of triamcinolone acetonide nasal aerosol in the treatment of perennial allergic rhinitis. Ann Allergy. 1990; 64: 300-5.

92. Vasar M, Houle PA, Douglass JA, et al. Fluticasone furoate nasal spray: effective monotherapy for symptoms of perennial allergic rhinitis in adults/adolescents. Allergy Asthma Proc. 2008; 29: 313-21.

93. Weinstein SF, Andrews CP, Shah SR, et al. Long-term efficacy and safety of once-daily treatment with beclomethasone dipropionate nasal aerosol. Allergy Asthma Proc. 2014; 35: 323-31.

94. Freche C, Leynadier F, Horak F, et al. Mizolastine provides effective symptom relief in patients suffering from perennial allergic rhinitis: a double-blind, placebocontrolled study versus loratadine. Ann Allergy Asthma Immunol. 2002; 89: 304-10.

95. Holmberg K, Tonnel AB, Dreyfus I, et al. Desloratadine relieves nasal congestion and improves quality-of-life in persistent allergic rhinitis. Allergy. 2009; 64: 1663-70.

96. Kim K, Sussman G, Hebert J, Lumry W, Lutsky B, Gates D. Desloratadine therapy for symptoms associated with perennial allergic rhinitis. Ann Allergy Asthma Immunol. 2006; 96: 460-5.

97. Garcia-Robaina JC, Sanchez I, de la Torre F, Fernandez-Caldas E, Casanovas M. Successful management of mite-allergic asthma with modified extracts of Dermatophagoides pteronyssinus and Dermatophagoides farinae in a doubleblind, placebo-controlled study. J Allergy Clin Immunol. 2006; 118: 1026-32.

98. McHugh SM, Lavelle B, Kemeny DM, Patel S, Ewan PW. A placebo-controlled trial of immunotherapy with two extracts of Dermatophagoides pteronyssinus in allergic rhinitis, comparing clinical outcome with changes in antigen-specific lgE, lgG, and IgG subclasses. J Allergy Clin Immunol. 1990; 86: 521-31.

99. Riechelmann H, Schmutzhard J, van der Werf JF, Distler A, Kleinjans HA. Efficacy and safety of a glutaraldehyde-modified house dust mite extract in allergic rhinitis. Am J Rhinol Allergy. 2010; 24: e104-9.

100. Varney VA, Tabbah K, Mavroleon G, Frew AJ. Usefulness of specific immunotherapy in 
patients with severe perennial allergic rhinitis induced by house dust mite: a doubleblind, randomized, placebo-controlled trial. Clin Exp Allergy. 2003; 33: 1076-82.

101. Demoly P, Emminger W, Rehm D, Backer V, Tommerup L, Kleine-Tebbe J. Effective treatment of house dust mite-induced allergic rhinitis with 2 doses of the SQ HDM SLITtablet: Results from a randomized doubleblind, placebo-controlled phase III trial. J Allergy Clin Immunol 2016; 137: 444-51.

102. Nolte $H$, Bernstein DI, Nelson HS, et al Efficacy of house dust mite SLIT-tablet in North American adolescents and adults in a randomized, placebo-controlled trial. J Allergy Clin Immunol. 2016; 138: 1631-8.

103. Okubo K, Masuyama K, Imai T, et al. Efficacy and safety of the SQ house dust mite sublingual immunotherapy tablet in Japanese adults and adolescents with house dust mite-induced allergic rhinitis. J Allergy Clin Immunol. 2017; 139: 1840-8.e10.

104. Patel P, Philip G, Yang W, et al. Randomized, double-blind, placebo-controlled study of montelukast for treating perennial allergic rhinitis. Ann Allergy Asthma Immunol. 2005; 95: 551-7.

105. Agertoft L, Wolthers OD, Fuglsang G, Pedersen S. Nasal powder administration of budesonide for seasonal rhinitis in children and adolescents. Pediatr Allergy Immunol. 1993; 4: 152-6.

106. Banov CH, Silvers WS, Green AW, et al. Placebo-controlled, double-blind study of the efficacy and safety of triamcinolone acetonide aerosol nasal inhaler in pediatric patients with seasonal allergic rhinitis. Clin Ther. 1996; 18: 265-72.

107. Georges G, Kim KT, Ratner P, Segall N, Qiu C. Effect of intranasal triamcinolone acetonide on basal hypothalamic-pituitary-adrenal axis function in children with allergic rhinitis. Allergy Asthma Proc. 2014; 35: 163-70.

108. Meltzer EO, Lee J, Tripathy I, Lim J, Ellsworth A, Philpot E. Efficacy and safety of oncedaily fluticasone furoate nasal spray in children with seasonal allergic rhinitis treated for 2 wk. Pediatr Allergy Immunol. 2009; 20: 279-86.

109. Storms WW, Segall N, Mansfield LE, et al. Efficacy and safety of beclomethasone dipropionate nasal aerosol in pediatric patients with seasonal allergic rhinitis. Ann Allergy Asthma Immunol. 2013; 111: 40814.e1.

110.Bufe A, Eberle P, Franke-Beckmann E, et al. Safety and efficacy in children of an SQ-standardized grass allergen tablet for sublingual immunotherapy. J Allergy Clin Immunol. 2009; 123: 167-73 e7.

111. Halken S, Agertoft L, Seidenberg J, et al. Five-grass pollen 300IR SLIT tablets: efficacy and safety in children and adolescents. Pediatr Allergy Immunol. 2010; 21: 970-6.

112. Berger W, Meltzer EO, Amar N, et al. Efficacy of MP-AzeFlu in children with seasonal allergic rhinitis: Importance of paediatric symptom assessment. Pediatr Allergy Immunol. 2016; 27: 126-33.

113. Meltzer EO, Blaiss M, Fairchild CJ. Comprehensive report of olopatadine $0.6 \%$ nasal spray as treatment for children with seasonal allergic rhinitis. Allergy Asthma Proc. 2011; 32: 213-20.

114. Razi C, Bakirtas A, Harmanci K, Turktas I, Erbas D. Effect of montelukast on symptoms and exhaled nitric oxide levels in 7- to 14-year-old children with seasonal allergic rhinitis. Ann Allergy Asthma Immunol. 2006; 97: 767-74.

115. Baena-Cagnani CE, Patel P. Efficacy and long-term safety of mometasone furoate nasal spray in children with perennial allergic rhinitis. Curr Med Res Opin. 2010; 26: 2047-55.

116. Berger WE, Jacobs RL, Amar NJ, Tantry SK, Li J, Small CJ. Efficacy and safety of beclomethasone dipropionate nasal aerosol in children with perennial allergic rhinitis. Ann Allergy Asthma Immunol. 2015; 115: 130-6.

117. Fokkens WJ, Cserhati E, dos Santos JM, et al. Budesonide aqueous nasal spray is an effective treatment in children with perennial allergic rhinitis, with an onset of action within 12 hours. Ann Allergy Asthma Immunol. 2002; 89: 279-84.

118. Maspero JF, Rosenblut A, Finn A, Jr., Lim J, Wu W, Philpot E. Safety and efficacy of fluticasone furoate in pediatric patients with perennial allergic rhinitis. Otolaryngol Head Neck Surg. 2008; 138: 30-7.

119. Weinstein S, Qaqundah P, Georges G, Nayak A. Efficacy and safety of triamcinolone acetonide aqueous nasal spray in children aged 2 to 5 years with perennial allergic rhinitis: a randomized, double-blind, placebo-controlled study with an open-label extension. Ann Allergy Asthma Immunol. 2009; 102: 339-47.

\section{Hendrik Nolte, MD, PhD}

ALK

US Highway 135 Route 202/206

Bedminster NJ 07921

\section{USA}

Tel: (+1) 5167671800

E-mail: Hendrik.nolte@alk.net 


\section{SUPPLEMENTARY MATERIAL}

\section{Methods}

Search strings used in database searches

The search string used to identify pharmacotherapy trials was: Allergic rhinitis[MeSH] AND (cetirizine[TIAB] OR loratadine[TIAB] OR desloratadine[TIAB] OR levocetirizine [TIAB] OR fexofenadine [TIAB] OR azelastine[TIAB] OR olopatadine[TIAB] OR Montelukast[TIAB] OR beclomethasone[TIAB] OR budesonide[TIAB] OR ciclesonide[TIAB] OR fluticasone[TIAB] OR mometasone[TIAB] OR triamcinolone[TIAB] OR pseudoephedrine[TIAB]) AND placebo[TIAB] NOT "review". The search string used to identify SLIT-tablet trials was: (immunotherapy[MeSH] OR desensitization, immunologic[MeSH]) AND (allergic rhinitis[MeSH] OR rhinoconjunctivitis) AND placebo[TIAB] NOT "review".

\section{Publication bias and heterogeneity assessment}

Publication biases across trials for each treatment class were assessed visually by funnel plots depicting the mean numerical difference in TNSS for each trial between active treatment and placebo on the $x$-axis and the standard error on the $y$-axis. Symmetric funnels (centered around the estimated mean effect size from the meta-analysis model) were viewed as evidence that publication bias was unlikely, whereas asymmetric funnels indicated a potential relationship between the effect size estimate (x-axis) and study precision (y-axis). The Egger's test was used to statistically assess publication bias across trials, which requires a $\mathrm{P}>0.05$ to reject the null hypothesis that the intercept is equal to zero in the population of studies being evaluated, indicating no publication bias. The Egger's test is sensitive to the number of studies being evaluated and requires that there be at least 10 trials in order to robustly indicate if publication bias exists ${ }^{(1)}$. An assessment of heterogeneity among the pooled trials was conducted. Both $\mathrm{I}^{2}$ (the ratio of the total heterogeneity divided by the total variability) and the Cochran's Q-test were computed. Interpretation of the $\mathrm{I}^{2}$ was guided by $\mathrm{I}^{2}$ of $<40 \%, 40 \%-60 \%$, and $>60 \%$, representing low, medium, and high heterogeneity, respectively. A Q-test with a $\mathrm{p}$-value $<0.1$ indicated high heterogeneity ${ }^{(1)}$.

\section{Imputation methods for standard deviations}

When standard deviations (SD) were not reported in the trial publications for use in the meta-analysis, a hierarchy of methods for imputation was used.

Step 1: When there was sufficient information reported on the end of assessment values ( $p$-values, $t$-stat, interquartile range $[I Q R]$, etc), then that information was used to compute the SD of the end of assessment directly by algebraic recalculation as previously described ${ }^{(2)}$. When algebraic recalculation was not possible, then approximation methods such as IQR were used. When algebraic recalculation or approximation methods were not possible and there was a sufficient number of studies to develop a sense for the distribution of the SD, then a prognostic method was used to impute the missing values ${ }^{(3)}$.

Step 2: When there was insufficient information about the SD of the end of assessment values but there was sufficient information on the change from baseline, the hierarchy of methods in Step 1 was used to develop an estimate of the SD of the change from baseline for the active treatment and placebo.

Step 3: Then the estimated SD of the change from baseline for the active treatment and placebo was used to estimate the SD of the end of assessment values for active treatment and placebo based on the formula for error propagation previously described (2).

Change in active treatment $(X)=$ End of Assessment active treatment $(A)$ - Baseline Value active treatment (B)

$$
\operatorname{Var}(\mathrm{X})=\operatorname{Var}(\mathrm{A})+\operatorname{Var}(\mathrm{B})-\operatorname{corr}^{*} \mathrm{SD}(\mathrm{A}) \mathrm{SD}(\mathrm{B})
$$

The correlation was imputed from the other trials that had complete data.

Step 4: In situations where there was no information on the SD/ var Baseline, an assumption was made that Var Baseline = Var End of Assessment. This resulted in:

$$
\begin{gathered}
\operatorname{Var}(\mathrm{X})=\operatorname{Var}(\mathrm{A})(2 \text {-corr }) \\
\mathrm{SD}(\mathrm{A})=\operatorname{sqrt}(\operatorname{Var} \mathrm{X} /(2 \text {-corr }))
\end{gathered}
$$


Table E1. Doses evaluated based on US Food and Drug Administration-approval. Doses are total daily dose.

\begin{tabular}{|c|c|c|}
\hline \multirow[t]{2}{*}{ Product } & \multicolumn{2}{|c|}{ Evaluated dose } \\
\hline & Aged $\geq 12$ y & Aged $<12$ y \\
\hline \multicolumn{3}{|l|}{ INCS } \\
\hline Beclomethasone dipropionate & $160-320 \mathrm{mcg}$ & $80 \mathrm{mcg}$ \\
\hline Budesonide & $64-256 \mathrm{mcg}$ & $64-128 \mathrm{mcg}$ \\
\hline Ciclesonide & $74-200 \mathrm{mcg}$ & $200 \mathrm{mcg}$ \\
\hline Fluticasone propionate & $100-200 \mathrm{mcg}$ & $100-200 \mathrm{mcg}$ \\
\hline Fluticasone furoate & $55-110 \mathrm{mcg}$ & $55-110 \mathrm{mcg}$ \\
\hline Mometasone furoate & $200 \mathrm{mcg}$ & $100 \mathrm{mcg}$ \\
\hline Triamcinolone acetonide & $110-220 \mathrm{mcg}$ & $110-220 \mathrm{mcg}$ \\
\hline \multicolumn{3}{|l|}{ Oral antihistamines } \\
\hline Cetirizine & $5-10 \mathrm{mg}$ & $2.5-10 \mathrm{mg}$ \\
\hline Loratadine & $10 \mathrm{mg}$ & $5-10 \mathrm{mg}$ \\
\hline Desloratadine & $5 \mathrm{mg}$ & $1-2.5 \mathrm{mg}$ \\
\hline Levocetirizine & $2.5-5 \mathrm{mg}$ & $1.25-2.5 \mathrm{mg}$ \\
\hline Fexofenadine & $180 \mathrm{mg}$ & $30-60 \mathrm{mg}$ \\
\hline \multicolumn{3}{|l|}{ Intranasal antihistamines } \\
\hline Azelastine & $\begin{array}{c}548-1644 \mathrm{mcg} \\
(0.1 \%-0.15 \% ; 1-2 \text { sprays per nostril BID) }\end{array}$ & $\begin{array}{l}548-822 \mathrm{mcg} \\
\text { b-0.15\%; } 1 \text { spray per nostril BID) }\end{array}$ \\
\hline Olopatadine & 5320 mcg (2 sprays per nostril BID) & 0 mcg (1 spray per nostril BID) \\
\hline \multicolumn{3}{|l|}{ Intranasal antihistamine/INCS } \\
\hline Azelastine/fluticason & $548 \mathrm{mcg} / 200 \mathrm{mcg}$ & $548 \mathrm{mcg} / 200 \mathrm{mcg}$ \\
\hline \multicolumn{3}{|l|}{ Oral LTRA } \\
\hline Montelukast & $10 \mathrm{mg}$ & $4-5 \mathrm{mg}$ \\
\hline \multicolumn{3}{|l|}{ Oral antihistamines/decongestants } \\
\hline Cetirizine/pseudoephedrine & $5-10 \mathrm{mg} / 120-240 \mathrm{mg}$ & Not approved \\
\hline Loratadine/pseudoephedrine & $5-10 \mathrm{mg} / 120-240 \mathrm{mg}$ & Not approved \\
\hline Desloratadine/pseudoephedrine & $2.5-5 \mathrm{mg} / 120-240 \mathrm{mg}$ & Not approved \\
\hline Fexofenadine/pseudoephedrine & $60-180 \mathrm{mg} / 120-240 \mathrm{mg}$ & Not approved \\
\hline \multicolumn{3}{|l|}{ SLIT-tablets } \\
\hline Timothy grass tablet & $2,800 \mathrm{BAU}(75,000 \mathrm{SQ}-\mathrm{T})$ & $2,800 \mathrm{BAU}(75,000 \mathrm{SQ}-\mathrm{T})$ \\
\hline 5-grass tablet & $300 \mathrm{IR}$ & $300 \mathrm{IR}$ \\
\hline Ragweed tablet & $12 \mathrm{Amb}$ a $1-\mathrm{U}$ & Not approved \\
\hline House dust mite tablet & 12 SQ-HDM & Not approved \\
\hline
\end{tabular}

BID, twice-daily; INCS, intranasal corticosteroid; LTRA, leukotriene receptor antagonist. 
Table E2. Pharmacotherapy trials in adults/adolescents included in the meta-analysis. ${ }^{*}$ Trial also included children $(<12 \mathrm{y})$.

\begin{tabular}{|c|c|c|c|c|}
\hline Author, Year & Allergy Type & Product, Daily Dose & $\begin{array}{l}\text { Rescue Symptom- } \\
\text { relieving Medication }\end{array}$ & Number Treated \\
\hline \multicolumn{5}{|l|}{ Oral antihistamines } \\
\hline Andrews et al, 2009, study $1^{4}$ & Seasonal & Fexofenadine, $180 \mathrm{mg}$ & no & Active: 311, Placebo: 313 \\
\hline Andrews et al, 2009, study $2^{4}$ & Seasonal & Fexofenadine, $180 \mathrm{mg}$ & no & Active: 227 , Placebo: 229 \\
\hline Anolik et al, $2008^{5}$ & Seasonal & Loratadine, $10 \mathrm{mg}$ & Allowed but unspecifie & Active: 181, Placebo: 176 \\
\hline Berger et al, $2003^{6}$ & Seasonal & Desloratadine, $5 \mathrm{mg}$ & Undocumented & Active: 111, Placebo: 111 \\
\hline Demoly et al, $2009^{7}$ & Seasonal & Desloratadine, $5 \mathrm{mg}$ & no & Active: 118, Placebo: 115 \\
\hline Dockhorn et al, $1987^{8}$ & Seasonal & Loratadine, $10 \mathrm{mg}$ & no & Active: 108, Placebo: 107 \\
\hline Ford et al, $2015^{9}$ & Seasonal & Cetirizine, $10 \mathrm{mg}$ & Undocumented & Active: 170, Placebo: 171 \\
\hline Hampel et al, $2004^{10}$ & Seasonal & Loratadine, $10 \mathrm{mg}$ & no & Active: 189, Placebo: 186 \\
\hline Kuna et al, $2009^{11}$ & Seasonal & Cetirizine, $10 \mathrm{mg}$ & no & Active: 227, Placebo: 225 \\
\hline Lu et al, 2009, study $1^{12}$ & Seasonal & Loratadine, $10 \mathrm{mg}$ & no & Active: 116, Placebo: 57 \\
\hline Lu et al, 2009 , study $2^{12}$ & Seasonal & Loratadine, 10 mg & no & Active: 164, Placebo: 54 \\
\hline Meltzer et al, $2000^{13}$ & Seasonal & Loratadine, $10 \mathrm{mg}$ & no & Active: 92, Placebo: 91 \\
\hline Nayak et al, $2002^{14}$ & Seasonal & Loratadine, $10 \mathrm{mg}$ & no & Active: 301 , Placebo: 149 \\
\hline Philip et al, $2002^{15}$ & Seasonal & Loratadine, $10 \mathrm{mg}$ & no & Active: 602, Placebo: 352 \\
\hline Pradalier et al, $2007^{16}$ & Seasonal & Desloratadine, $5 \mathrm{mg}$ & no & Active: 234 , Placebo: 249 \\
\hline Ratner et al, $1998^{17}$ & Seasonal & Loratadine, $10 \mathrm{mg}$ & no & Active: 150, Placebo: 150 \\
\hline Skassa-Brociek et al, $1988^{18}$ & Seasonal & Loratadine, $10 \mathrm{mg}$ & no & Active: 22, Placebo: 24 \\
\hline Van Adelsberg et al, $2003^{19}$ & Seasonal & Loratadine, $10 \mathrm{mg}$ & no & Active: 171, Placebo: 521 \\
\hline Freche et al, $2002^{20}$ & Perennial & Loratadine, $10 \mathrm{mg}$ & no & Active: 140, Placebo: 146 \\
\hline Holmberg et al, $2009^{21}$ & Perennial & Desloratadine, $5 \mathrm{mg}$ & no & Active: 293, Placebo: 291 \\
\hline Kim et al, $2006^{22}$ & Perennial & Desloratadine, $5 \mathrm{mg}$ & no & Active: 591, Placebo: 588 \\
\hline \multicolumn{5}{|l|}{ INCS } \\
\hline Andrews et al, $2009^{4}$ & Seasonal & Fluticasone furoate, $110 \mathrm{mcg}$ & no & Active: 224 Placebo: 229 \\
\hline Anolik et al, $2008^{5}$ & Seasonal & Mometasone, $200 \mathrm{mcg}$ & Allowed but unspecifie & Active: 176 Placebo: 176 \\
\hline Bronsky et al, $1997^{23}$ & Seasonal & Mometasone, $200 \mathrm{mcg}$ & no & Active: 96 Placebo: 95 \\
\hline Bronsky et al, $1996^{24}$ & Seasonal & Fluticasone propionate, $200 \mathrm{mcg}$ & no & Active: 117 Placebo: 115 \\
\hline Carr et al, 2012, Study $1^{25}$ & Seasonal & Fluticasone propionate, $200 \mathrm{mcg}$ & no & Active: 207 Placebo: 209 \\
\hline Carr et al, 2012, study $2^{25}$ & Seasonal & Fluticasone propionate, $200 \mathrm{mcg}$ & no & Active: 189 Placebo: 200 \\
\hline Carr et al, 2012, study $3^{25}$ & Seasonal & Fluticasone propionate, $200 \mathrm{mcg}$ & no & Active: 450 Placebo: 448 \\
\hline Creticos et al, $1998^{26 *}$ & Seasonal & Budesonide, $128 \mathrm{mcg}$ & $\begin{array}{l}\text { Chlorpheniramine maleate } \\
4 \mathrm{mg} \text { tablets }\end{array}$ & Active: 83 Placebo: 83 \\
\hline Di Lorenzo et al, $1999^{27}$ & Seasonal & Fluticasone propionate, $200 \mathrm{mcg}$ & Undocumented & Active: 8 Placebo: 8 \\
\hline Di Lorenzo et al, $2004^{28}$ & Seasonal & Fluticasone propionate, $200 \mathrm{mcg}$ & Undocumented & Active: 20 Placebo: 20 \\
\hline Dykewicz et al, $2003^{29}$ & Seasonal & Fluticasone propionate, $200 \mathrm{mcg}$ & no & Active: 122 Placebo: 119 \\
\hline Findlay et al, $1992^{30}$ & Seasonal & Triamcinolone, $220 \mathrm{mcg}$ & Undocumented & Active:79 Placebo: 75 \\
\hline Fokkens et al, $2007^{31}$ & Seasonal & Fluticasone furoate, $110 \mathrm{mcg}$ & no & Active: 141 Placebo: 144 \\
\hline Ford et al, $2015^{9}$ & Seasonal & Fluticasone propionate, $200 \mathrm{mcg}$ & Undocumented & Active: 170 Placebo: 171 \\
\hline Graft et al, $1996^{32}$ & Seasonal & Mometasone, $200 \mathrm{mcg}$ & no & Active: 114 Placebo: 104 \\
\hline Graft et al, $1996^{32}$ & Seasonal & Beclomethasone, $336 \mathrm{mcg}$ & no & Active: 112 Placebo: 104 \\
\hline Hampel et al, $2010^{33}$ & Seasonal & Fluticasone propionate, $200 \mathrm{mcg}$ & no & Active: 151 Placebo: 151 \\
\hline Jacobs et al, $2009^{34}$ & Seasonal & Fluticasone furoate, $110 \mathrm{mcg}$ & no & Active: 152 Placebo: 150 \\
\hline Kaiser et al, $2007^{35}$ & Seasonal & Fluticasone furoate, $110 \mathrm{mcg}$ & no & Active: 151 Placebo: 148 \\
\hline Mansfield et a, $2007^{36}$ & Seasonal & Fluticasone propionate, $200 \mathrm{mcg}$ & Undocumented & Active: 16 Placebo: 16 \\
\hline Martin et al, $2007^{37}$ & Seasonal & Fluticasone furoate, $110 \mathrm{mcg}$ & no & Active: 127 Placebo: 128 \\
\hline
\end{tabular}




\begin{tabular}{|c|c|c|c|c|}
\hline Author, Year & Allergy Type & Product, Daily Dose & $\begin{array}{l}\text { Rescue Symptom- } \\
\text { relieving Medication }\end{array}$ & Number Treated \\
\hline Meltzer et al, $1998^{38}$ & Seasonal & Mometasone, $200 \mathrm{mcg}$ & no & Active: 85 Placebo: 43 \\
\hline Meltzer et al, $2011^{39}$ & Seasonal & Mometasone, $200 \mathrm{mcg}$ & Undocumented & Active: 344 Placebo: 340 \\
\hline Munk et al, $1997^{40}$ & Seasonal & Triamcinolone, $220 \mathrm{mcg}$ & no & Active: 56 Placebo: 56 \\
\hline Munk et al, $1996^{41}$ & Seasonal & Triamcinolone, $220 \mathrm{mcg}$ & no & Active: 70 Placebo: 70 \\
\hline Okubo et al, $2009^{42}$ & Seasonal & Fluticasone furoate, $110 \mathrm{mcg}$ & no & Active: 147 Placebo: 70 \\
\hline Prenner et al, $2010^{43}$ & Seasonal & Mometasone, $200 \mathrm{mcg}$ & no & Active: 220 Placebo: 209 \\
\hline Pullerits et al, $2002^{44}$ & Seasonal & Fluticasone propionate, 200 mcg & $\begin{array}{l}\text { cromoglycate eyedrops; } \\
\text { loratadine tablets }\end{array}$ & Active: 13 Placebo: 18 \\
\hline Raphael et al, $2013^{45}$ & Seasonal & Beclomethasone, $320 \mathrm{mcg}$ & no & Active: 122 Placebo: 123 \\
\hline Ratner et al, $1998^{17}$ & Seasonal & Fluticasone propionate, $200 \mathrm{mcg}$ & no & Active: 150 Placebo: 150 \\
\hline Ratner et al, $2006^{46}$ & Seasonal & Ciclesonide, $200 \mathrm{mcg}$ & Undocumented & Active: 164 Placebo: 163 \\
\hline Rosenthal et al, $1998^{47}$ & Seasonal & Triamcinolone, $200 \mathrm{mcg}$ & Undocumented & Active: 94 Placebo: 96 \\
\hline Schenkel et al, $2013^{48}$ & Seasonal & Triamcinolone, $110 \mathrm{mcg}$ & no & Active: 107 Placebo: 111 \\
\hline Steensen et al, $1981^{49}$ & Seasonal & Budesonide, $200 \mathrm{mcg}$ & $\begin{array}{l}\text { dexchlorpheniramine } \\
\text { maleate } 2 \mathrm{mg} \text {; antazolinhy- } \\
\text { drochloride eyedrops }\end{array}$ & Active: 14 Placebo: 12 \\
\hline Stern et al, $1997^{50}$ & Seasonal & Budesonide, $256 \mathrm{mcg}$ & $\begin{array}{l}\text { terfenadine } 60 \mathrm{mg} \text { QD/BID; } \\
\text { disodium cromoglycate } \\
\text { eye drops } 20 \mathrm{mg} / \mathrm{ml}, 1-8 \\
\text { drops } / \mathrm{d}\end{array}$ & Active: 182 Placebo: 59 \\
\hline Stern et al, $1997^{50}$ & Seasonal & Fluticasone propionate, 200 & $\begin{array}{l}\text { terfenadine } 60 \mathrm{mg} \text { QD/BID; } \\
\text { disodium cromoglycate } \\
\text { eye drops } 20 \mathrm{mg} / \mathrm{ml}, 1-8 \\
\text { drops/d }\end{array}$ & Active: 180 Placebo: 59 \\
\hline Tinkelman et al, $1990^{51}$ & Seasonal & Triamcinolone, $110 \mathrm{mcg}$ & no & Active: 81 Placebo: 87 \\
\hline Van Bavel et al, $2012^{52}$ & Seasonal & Beclomethasone, $320 \mathrm{mcg}$ & no & Active: 167 Placebo: 171 \\
\hline Bende et al, $2002^{53}$ & Perennial & Budesonide, $256 \mathrm{mcg}$ & loratadine $10 \mathrm{mg} Q D$ & Active: 107 Placebo: 114 \\
\hline Bende et al, $2002^{53}$ & Perennial & Mometasone, $200 \mathrm{mcg}$ & loratadine $10 \mathrm{mg}$ QD & Active: 106 Placebo: 114 \\
\hline Chervinsky et al, $2007^{54}$ & Perennial & Ciclesonide, $200 \mathrm{mcg}$ & Undocumented & Active: 441 Placebo: 222 \\
\hline Given et al, $2010^{55}$ & Perennial & Fluticasone furoate, $110 \mathrm{mcg}$ & no & Active: 160 Placebo: 155 \\
\hline Kivisaari et al, $2001^{56}$ & Perennial & Fluticasone propionate, $200 \mathrm{mcg}$ & Undocumented & Active: 110 Placebo: 108 \\
\hline Kobayashi et al, $1995^{57}$ & Perennial & Triamcinolone, $220 \mathrm{mcg}$ & no & Active: 88 Placebo: 90 \\
\hline Meltzer et al, $1998^{58 *}$ & Perennial & Budesonide, $256 \mathrm{mcg}$ & Undocumented & Active: 96 Placebo: 97 \\
\hline Meltzer et al, $2012^{59}$ & Perennial & Beclomethasone, $320 \mathrm{mcg}$ & no & Active: 232 Placebo: 234 \\
\hline Meltzer et al, $2007^{60}$ & Perennial & Ciclesonide, $200 \mathrm{mcg}$ & Undocumented & Active: 238 Placebo: 233 \\
\hline Mohar et al, $2012^{61}$ & Perennial & Ciclesonide, $148 \mathrm{mcg}$ & no & Active: 505 Placebo: 307 \\
\hline Nathan et al, $2008^{62}$ & Perennial & Fluticasone furoate, $110 \mathrm{mcg}$ & no & Active: 149 Placebo: 153 \\
\hline Spector et al, $1990^{63}$ & Perennial & Triamcinolone, $100 \mathrm{mcg}$ & no & Active: 94 Placebo: 94 \\
\hline Vasar et al, $2008^{64}$ & Perennial & Fluticasone furoate, $110 \mathrm{mcg}$ & no & Active: 151 Placebo: 151 \\
\hline Weinstein et al, $2014^{65}$ & Perennial & Beclomethasone, $320 \mathrm{mcg}$ & Allowed but unspecifie & Active: 414 Placebo: 110 \\
\hline \multicolumn{5}{|l|}{ Montelukast } \\
\hline Lu et al, 2009, study $1^{12}$ & Seasonal & Montelukast, $10 \mathrm{mg}$ & no & Active: 112 Placebo: 57 \\
\hline Lu et al, 2009 , study $2^{12}$ & Seasonal & Montelukast, $10 \mathrm{mg}$ & no & Active: 103 Placebo: 54 \\
\hline Meltzer et al, $2000^{13}$ & Seasonal & Montelukast, $10 \mathrm{mg}$ & no & Active: 95 Placebo: 91 \\
\hline Nayak et al, $2002^{14}$ & Seasonal & Montelukast, $10 \mathrm{mg}$ & no & Active: 155 Placebo: 149 \\
\hline Okubo et al, $2008^{66}$ & Seasonal & Montelukast, $10 \mathrm{mg}$ & Undocumented & Active: 310 Placebo: 314 \\
\hline Philip et al, $2002^{15}$ & Seasonal & Montelukast, $10 \mathrm{mg}$ & no & Active: 348 Placebo: 352 \\
\hline Philip et al, $2004^{67}$ & Seasonal & Montelukast, $10 \mathrm{mg}$ & no & Active: 415 Placebo: 416 \\
\hline Pullerits et al, $2002^{44}$ & Seasonal & Montelukast, $10 \mathrm{mg}$ & $\begin{array}{l}\text { cromoglycate eyedrops; } \\
\text { loratadine tablets }\end{array}$ & Active: 16 Placebo: 18 \\
\hline
\end{tabular}




\begin{tabular}{|c|c|c|c|c|}
\hline Author, Year & Allergy Type & Product, Daily Dose & $\begin{array}{l}\text { Rescue Symptom- } \\
\text { relieving Medication }\end{array}$ & Number Treated \\
\hline Van Adelsberg et al, $2003^{68}$ & Seasonal & Montelukast, $10 \mathrm{mg}$ & no & Active: 448 Placebo: 451 \\
\hline Van Adelsberg et al, $2003^{19}$ & Seasonal & Montelukast, $10 \mathrm{mg}$ & no & Active: 522 Placebo: 521 \\
\hline Patel et al, $2005^{69}$ & Perennial & Montelukast, $10 \mathrm{mg}$ & no & Active: 1002 Placebo: 990 \\
\hline \multicolumn{5}{|l|}{ Intranasal antihistamines } \\
\hline Berger et al, $2003^{6}$ & Seasonal & Azelastine, $548 \mathrm{mcg}$ & Undocumented & Active: 108 Placebo: 111 \\
\hline Bernstein et al, $2009^{70}$ & Seasonal & Azelastine, $548 \mathrm{mcg}$ & no & Active: 146 Placebo: 138 \\
\hline Carr et al, 2012, study $1^{25}$ & Seasonal & Azelastine, $548 \mathrm{mcg}$ & no & Active: 208 Placebo: 209 \\
\hline Carr et al, 2012 , study $2^{25}$ & Seasonal & Azelastine, $548 \mathrm{mcg}$ & no & Active: 194 Placebo: 200 \\
\hline Carr et al, 2012 , study $3^{25}$ & Seasonal & Azelastine, $548 \mathrm{mcg}$ & no & Active: 445 Placebo: 448 \\
\hline Hampel et al, $2010^{33}$ & Seasonal & Azelastine, $548 \mathrm{mcg}$ & no & Active: 152 Placebo: 151 \\
\hline Howland et al, $2011^{71}$ & Seasonal & Azelastine, $822 \mathrm{mcg}$ & no & Active: 251 Placebo: 254 \\
\hline LaForce et al, $2004^{72}$ & Seasonal & Azelastine, $548 \mathrm{mcg}$ & no & Active: 112 Placebo: 111 \\
\hline Lumry et al, 2007 , study $1^{73}$ & Seasonal & Azelastine, $548 \mathrm{mcg}$ & no & Active: 139 Placebo: 141 \\
\hline Lumry et al, 2007 , study $2^{73}$ & Seasonal & Azelastine, $548 \mathrm{mcg}$ & no & Active: 137 Placebo: 137 \\
\hline Shah et al, $2009^{74}$ & Seasonal & Azelastine, $822 \mathrm{mcg}$ & no & Active: 177 Placebo: 177 \\
\hline Shah et al, $2009^{75}$ & Seasonal & Olopatadine, $5320 \mathrm{mcg}$ & Undocumented & Active: 180 Placebo: 176 \\
\hline Van Bavel et al, $2009^{76}$ & Seasonal & Azelastine, $822 \mathrm{mcg}$ & no & Active: 266 Placebo: 266 \\
\hline \multicolumn{5}{|c|}{ Combination intranasal antihistamine/INCS } \\
\hline Carr et al, 2012, study $1^{25}$ & Seasonal & $\begin{array}{l}\text { Azelastine }+ \text { fluticasone } p \\
\text { nate, } 548 \mathrm{mcg} / 200 \mathrm{mcg}\end{array}$ & no & Active: 207 Placebo: 209 \\
\hline Carr et al, 2012 , study $2^{25}$ & Seasonal & $\begin{array}{l}\text { Azelastine + fluticasone p opio- } \\
\text { nate, } 548 \mathrm{mcg} / 200 \mathrm{mcg}\end{array}$ & no & Active: 193 Placebo: 200 \\
\hline Carr et al, 2012, study $3^{25}$ & Seasonal & $\begin{array}{l}\text { Azelastine + fluticasone p opio- } \\
\text { nate, } 548 \mathrm{mcg} / 200 \mathrm{mcg}\end{array}$ & no & Active: 448 Placebo: 448 \\
\hline Hampel et al, $2010^{33}$ & Seasonal & $\begin{array}{l}\text { Azelastine + fluticasone p opio- } \\
\text { nate, } 548 \mathrm{mcg} / 200 \mathrm{mcg}\end{array}$ & no & Active: 153 Placebo: 151 \\
\hline \multicolumn{5}{|c|}{ Combination oral antihistamine/decongestant } \\
\hline Nathan et al, $2006^{77}$ & Seasonal & $\begin{array}{l}\text { Cetirizine + pseudoephedrine, } 5 \\
\mathrm{mg} / 120 \mathrm{mg}\end{array}$ & no & Active: 139 Placebo: 135 \\
\hline
\end{tabular}

BID, twice-daily; INCS, intranasal corticosteroid; QD, once-daily. 
Table E3. Pharmacotherapy trials in children included in the meta-analysis.

\begin{tabular}{|c|c|c|c|c|}
\hline Author, Year & Allergy Type & Product, Daily Dose & $\begin{array}{l}\text { Rescue Symptom- } \\
\text { relieving Medication }\end{array}$ & Number Treated \\
\hline \multicolumn{5}{|l|}{ Oral antihistamines } \\
\hline \multicolumn{5}{|l|}{ No eligible studies } \\
\hline \multicolumn{5}{|l|}{ INCS } \\
\hline Agertoft et al, $1993^{78}$ & Seasonal & Budesonide, $400 \mathrm{mcg}$ & terfenadine $60 \mathrm{mg}$ tablets & Active: 27 Placebo: 29 \\
\hline Banov et al, $1996^{79}$ & Seasonal & Triamcinalone, $220 \mathrm{mcg}$ & no & Active: 58 Placebo: 58 \\
\hline Georges et al, 2014 & Seasonal & $\begin{array}{l}\text { Triamcinalone, 110/220 } \\
\text { mcg }\end{array}$ & loratadine $5 \mathrm{mg} / \mathrm{mL}$ syrup & Active: 69 Placebo: 71 \\
\hline Meltzer et al, $2009^{81}$ & Seasonal & $\begin{array}{l}\text { Fluticasone furoate, } 110 \\
\mathrm{mcg}\end{array}$ & $\begin{array}{l}\text { subjects aged } 6-11 \text { yr did not receive } \\
\text { rescue symptom-relieving medication; } \\
\text { subjects aged } 2 \text { to }<6 \text { yr were provided } \\
\text { loratadine } 1 \mathrm{mg} / \mathrm{ml} \text { syrup }\end{array}$ & Active: 184 Placebo: 186 \\
\hline Storms et al, $2013^{82}$ & Seasonal & Beclomethasone, $160 \mathrm{mcg}$ & no & Active: 241 Placebo: 234 \\
\hline Baena-Cagna et al, $2010^{83}$ & Perennial & Mometasone, $100 \mathrm{mcg}$ & Undocumented & Active: 190 Placebo: 191 \\
\hline Berger et al, $2015^{84}$ & Perennial & Beclomethasone, $80 \mathrm{mcg}$ & $\begin{array}{l}\text { subjects aged } 4-5 \text { yr: loratadine } 5 \mathrm{mg} \text { tablet } \\
\text { or } 5 \mathrm{~mL}(1 \mathrm{mg} / \mathrm{mL} \text { ) syrup } \mathrm{QD} \text {; subjects aged } \\
6-11 \mathrm{yr} \text { : loratadine } 10 \mathrm{mg} \text { tablet or } 10 \mathrm{~mL}(1 \\
\mathrm{mg} / \mathrm{mL} \text { ) syrup QD during first } 6 \text { eeks }\end{array}$ & Active: 362 Placebo: 185 \\
\hline Fokkens et al, $2002^{85}$ & Perennial & Budesonide, $128 \mathrm{mcg}$ & cetirizine $10 \mathrm{mg}$ QD & Active: 100 Placebo: 102 \\
\hline Maspero et al, $2008^{86}$ & Perennial & $\begin{array}{l}\text { Fluticasone furoate, } 110 \\
\mathrm{mcg}\end{array}$ & no & Active: 185 Placebo: 188 \\
\hline Weinstein et al, $2009^{87}$ & Perennial & Triamcinolone, $110 \mathrm{mcg}$ & loratadine syrup $5 \mathrm{mg}$ QD & Active: 231 Placebo: 233 \\
\hline \multicolumn{5}{|l|}{ Montelukast } \\
\hline Razi et al, $2006^{88}$ & Seasonal & Montelukast, $5 \mathrm{mg}$ & no & Active: 29 Placebo: 28 \\
\hline \multicolumn{5}{|l|}{ Intranasal antihistamines } \\
\hline Meltzer et al, $2011^{89}$ & Seasonal & Olopatadine, 2660 mcg & no & Active: 471 Placebo: 473 \\
\hline \multicolumn{5}{|c|}{ Combination intranasal antihistamine/INCS } \\
\hline Berger et al, $2016^{90}$ & Seasonal & $\begin{array}{l}\text { Azelastine + fluticasone } \\
\text { propionate, } 548 \mathrm{mcg} / 200 \\
\text { mcg }\end{array}$ & Undocumented & Active: 152 Placebo: 152 \\
\hline
\end{tabular}

INCS, intranasal corticosteroid; QD, once-daily. 
Table E4. Sublingual immunotherapy tablet trials in adults/adolescents included in the meta-analysis. ${ }^{*}$ Trial also included children ( $\left.\geq 5 \mathrm{y}\right)$.

\begin{tabular}{|c|c|c|c|c|c|c|c|}
\hline Author, Year & $\begin{array}{l}\text { Allergy } \\
\text { Type }\end{array}$ & Product & $\begin{array}{l}\text { Induction } \\
\text { Dose Range }\end{array}$ & $\begin{array}{l}\text { Maintenance } \\
\text { Dose }\end{array}$ & $\begin{array}{l}\text { Allergen Con- } \\
\text { tent }\end{array}$ & $\begin{array}{l}\text { Rescue Symptom-relieving } \\
\text { Medication }\end{array}$ & $\begin{array}{l}\text { Number } \\
\text { Treated }\end{array}$ \\
\hline $\begin{array}{l}\text { Creticos et } \\
\text { al, } 2013^{91}\end{array}$ & Seasonal & $\begin{array}{l}\text { ragweed } \\
\text { SLIT-tablet } \\
\text { (Ragwitek) }\end{array}$ & $\begin{array}{l}12 \mathrm{Amb} a \\
1-\mathrm{U}\end{array}$ & $12 \mathrm{Amb}$ a $1-\mathrm{U}$ & NA & $\begin{array}{l}\text { loratadine } 10 \mathrm{mg} \text { tablet } \\
\text { QD; olopatadine } \mathrm{HCl} 0.1 \% \\
\text { ophthalmic solution; mome- } \\
\text { tasone furoate nasal spray } 50 \\
\text { mcg; prednisone } 5 \mathrm{mg} \text { tablet }\end{array}$ & $\begin{array}{l}\text { Active: } 194 \\
\text { Placebo: } 198\end{array}$ \\
\hline $\begin{array}{l}\text { Dahl et al, } \\
2006^{92}\end{array}$ & Seasonal & $\begin{array}{l}\text { Tim grass } \\
\text { SLIT-tablet } \\
\text { (Grastek) }\end{array}$ & 75,000 SQ-T & 75,000 SQ-T & $\begin{array}{l}75,000 \text { SQ-T=15 } \\
\text { mcg Phl p } 5\end{array}$ & $\begin{array}{l}\text { desloratadine } 5 \text { mg QD; } \\
\text { budesonide nasal spray } 32 \\
\text { mcg (max } 2 \text { puffs per nostril } \\
\text { BID); prednisone } 5 \text { mg tablet } \\
\text { (max } 50 \text { mg/day) }\end{array}$ & $\begin{array}{l}\text { Active: } 316 \\
\text { Placebo: } 318\end{array}$ \\
\hline $\begin{array}{l}\text { Maloney et } \\
\text { al, 2014 }\end{array}$ & Seasonal & $\begin{array}{l}\text { Tim grass } \\
\text { SLIT-tablet } \\
\text { (Grastek) }\end{array}$ & 75,000 SQ-T & 75,000 SQ-T & $\begin{array}{l}75,000 \text { SQ-T=15 } \\
\text { mcg Phl p } 5\end{array}$ & $\begin{array}{l}\text { oral antihistamines (unspe- } \\
\text { cified); ocular a tihistamines } \\
\text { (unspecified); i tranasal } \\
\text { corticosteroids (unspecified); } \\
\text { oral corticosteroids (unspe- } \\
\text { cified) }\end{array}$ & $\begin{array}{l}\text { Active: } 752 \\
\text { Placebo: } 749\end{array}$ \\
\hline $\begin{array}{l}\text { Nelson et al, } \\
2011^{94}\end{array}$ & Seasonal & $\begin{array}{l}\text { Tim grass } \\
\text { SLIT-tablet } \\
\text { (Grastek) }\end{array}$ & 75,000 SQ-T & $75,000 \mathrm{SQ}-\mathrm{T}$ & $\begin{array}{l}75,000 \text { SQ-T=15 } \\
\text { mcg Phl p } 5\end{array}$ & $\begin{array}{l}\text { loratadine } 10 \text { mg tablet } \\
\text { QD; olopatadine } \mathrm{HCl} 0.1 \% \\
\text { ophthalmic solution (max } 1 \\
\text { drop in the affected eye BID); } \\
\text { mometasone furoate nasal } \\
\text { spray } 50 \mathrm{mcg} \text { (max } 2 \text { sprays } \\
\text { in each nostril QD); pred- } \\
\text { nisone } 5 \mathrm{mg} \text { tablet (day } 1 \text {, } \\
1 \mathrm{mg} / \mathrm{kg} / \mathrm{d} \text {, maximum of } 50 \\
\mathrm{mg} / \mathrm{d} \text {; day } 21,0.5 \mathrm{mg} / \mathrm{kg} / \mathrm{d} \text {, } \\
\text { maximum of } 25 \mathrm{mg} / \mathrm{d} \text { ) }\end{array}$ & $\begin{array}{l}\text { Active: } 213 \\
\text { Placebo: } 225\end{array}$ \\
\hline $\begin{array}{l}\text { Demoly et } \\
\text { al, } 2016^{95}\end{array}$ & Perennial & $\begin{array}{l}\text { HDM SLIT-ta- } \\
\text { blet (Odactra) }\end{array}$ & 12 SQ-HDM & & NA & $\begin{array}{l}\text { desloratadine } 5 \text { mg QD or } \\
\text { budesonide } 64 \text { mcg (max } \\
\text { dose } 2 \text { puffs per nostril } \\
\text { QD); azelastine } 0.05 \% \text {, or } \\
\text { lodoxamide tromethamine } \\
0.1 \% \text { [in Croatia only], none } \\
\text { [in Serbia only] (max } 2 \text { drops } \\
\text { per eye QD) }\end{array}$ & $\begin{array}{l}\text { Active: } 318 \\
\text { Placebo: } 338\end{array}$ \\
\hline $\begin{array}{l}\text { Nolte et al, } \\
2016^{96}\end{array}$ & Perennial & $\begin{array}{l}\text { HDM SLIT-ta- } \\
\text { blet (Odactra) }\end{array}$ & $12 \mathrm{~s}$ & 12 SQ-HDM & $\begin{array}{l}12 \text { SQ-HDM=15 } \\
\text { mcg group } 1 \\
\text { and } 15 \text { mcg } \\
\text { group } 2\end{array}$ & $\begin{array}{l}\text { loratadine } 10 \text { mg tablet QD; } \\
\text { mometasone nasal spray } 50 \\
\text { mcg (max } 2 \text { sprays per nostril } \\
\text { QD); olopatadine hydrochlo- } \\
\text { ride, } 0.1 \% \text { (max } 1 \text { drop per } \\
\text { eye BID) }\end{array}$ & $\begin{array}{l}\text { Active: } 741 \\
\text { Placebo: } 741\end{array}$ \\
\hline $\begin{array}{l}\text { Okubo et al, } \\
2017^{97}\end{array}$ & Perennial & $\begin{array}{l}\text { HDM SLIT-ta- } \\
\text { blet (Odactra) }\end{array}$ & 12 SQ-HDM & 12 SQ-HDM & NA & $\begin{array}{l}\text { antihistamine tablets } \\
\text { (unspecified); e e drops (un- } \\
\text { specified); or nasal s eroids } \\
\text { (unspecified }\end{array}$ & $\begin{array}{l}\text { Active: } 314 \\
\text { Placebo: } 319\end{array}$ \\
\hline
\end{tabular}

BID, twice-daily; IR, arbitrary index of reactivity; HDM, house dust mite; QD, daily; SLIT, sublingual immunotherapy; SQ, a method of standardisation of biological potency, major allergen content, and complexity of the allergen extract. 
Table E5. Sublingual immunotherapy tablet trials in children included in the meta-analysis.

\begin{tabular}{|c|c|c|c|c|c|c|c|}
\hline Author, Year & $\begin{array}{l}\text { Allergy } \\
\text { Type }\end{array}$ & Product & $\begin{array}{l}\text { Induction } \\
\text { Dose Range }\end{array}$ & $\begin{array}{l}\text { Maintenance } \\
\text { Dose }\end{array}$ & $\begin{array}{l}\text { Allergen Con- } \\
\text { tent }\end{array}$ & $\begin{array}{l}\text { Rescue Symptom-relieving } \\
\text { Medication }\end{array}$ & $\begin{array}{l}\text { Number } \\
\text { Treated }\end{array}$ \\
\hline $\begin{array}{l}\text { Bufe et al, } \\
2009^{98}\end{array}$ & Seasonal & $\begin{array}{l}\text { Tim grass } \\
\text { SLIT-tablet } \\
\text { (Grastek) }\end{array}$ & 75,000 SQ-T & 75,000 SQ-T & $\begin{array}{l}75,000 \text { SQ-T }=15 \\
\text { mcg Phl p } 5\end{array}$ & $\begin{array}{l}\text { loratadine tablets; levoca- } \\
\text { bastine eye drops; budeso- } \\
\text { nide nasal spray; salbutamol } \\
\text { spray; fluticasone inhale ; } \\
\text { and prednisolone tablets }\end{array}$ & $\begin{array}{l}\text { Active: } 126 \\
\text { Placebo: } 127\end{array}$ \\
\hline $\begin{array}{l}\text { Halken et al, } \\
2010^{99}\end{array}$ & Seasonal & $\begin{array}{l}5 \text { grass SLIT- } \\
\text { tablet (Oralair) }\end{array}$ & 100 IR-300 IR & $300 \mathrm{IR}$ & $\begin{array}{l}300 \mathrm{IR}=20 \mathrm{mcg} \\
\text { group } 5 \text { aller- } \\
\text { gens }\end{array}$ & $\begin{array}{l}\text { antihistamine (unspecified); } \\
\text { intranasal corticosteroid (un- } \\
\text { specified); o al corticosteroid } \\
\text { (unspecified }\end{array}$ & $\begin{array}{l}\text { Active: } 131 \\
\text { Placebo: } 135\end{array}$ \\
\hline
\end{tabular}

IR, arbitrary index of reactivity; SLIT, sublingual immunotherapy; SQ, a method of standardisation of biological potency, major allergen content, and complexity of the allergen extract.

Figure E1. Mean difference from placebo in total nasal symptom score in adult/adolescent seasonal allergic rhinitis (SAR) for A) INCS, B) oral antihistamines, C) intranasal antihistamines, D) montelukast, E) combination intranasal antihistamines/INCS, and F) SLIT-tablets. INCS, intranasal corticosteroids; SLIT, sublingual immunotherapy.

Adult SAR: INCS

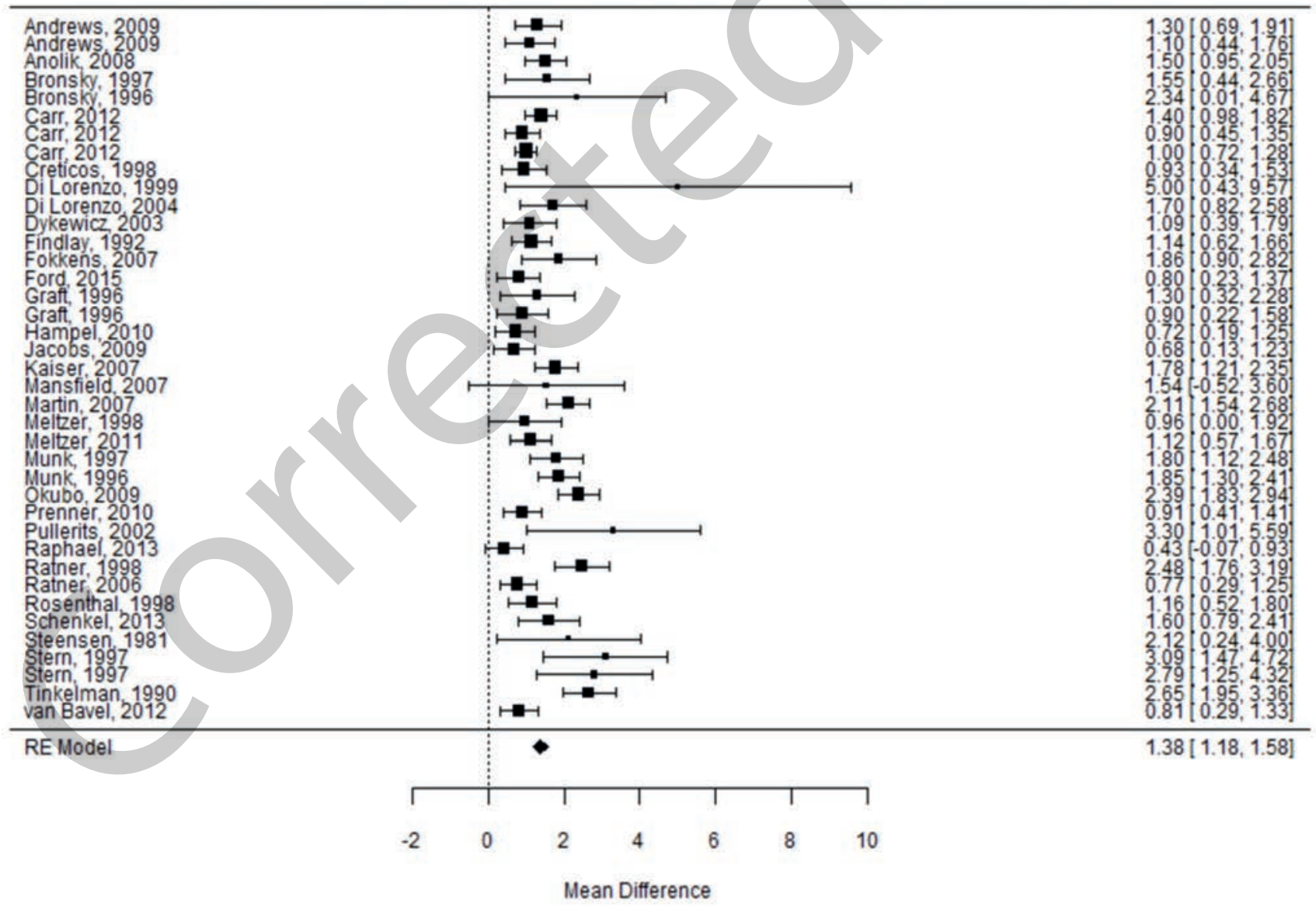


B

Adult SAR: Oral Antihistamines

\begin{tabular}{ll}
\hline Andrews et al, 2009 \\
Andrews et al, 2009 \\
Anolik, 2008 \\
Berger, White, 2003 \\
Demoly et al, 2009 \\
Dockhorn et al, 1987 \\
Ford et al, 2015 \\
Hampel et al, 2004 \\
Kuna et al, 2009 \\
Lu. et al, 2009 \\
Lu et al, 2009 \\
Meltzer et al, 2000 \\
Nayak et al, 2002 \\
Philip, 2002 \\
Pradalier et al, 2007 \\
Ratner et al, 1998 \\
Skassa-Brociek et al, 1988 \\
van Adelsberg, 2003
\end{tabular}

C

Adult SAR: Intranasal Antihistamines

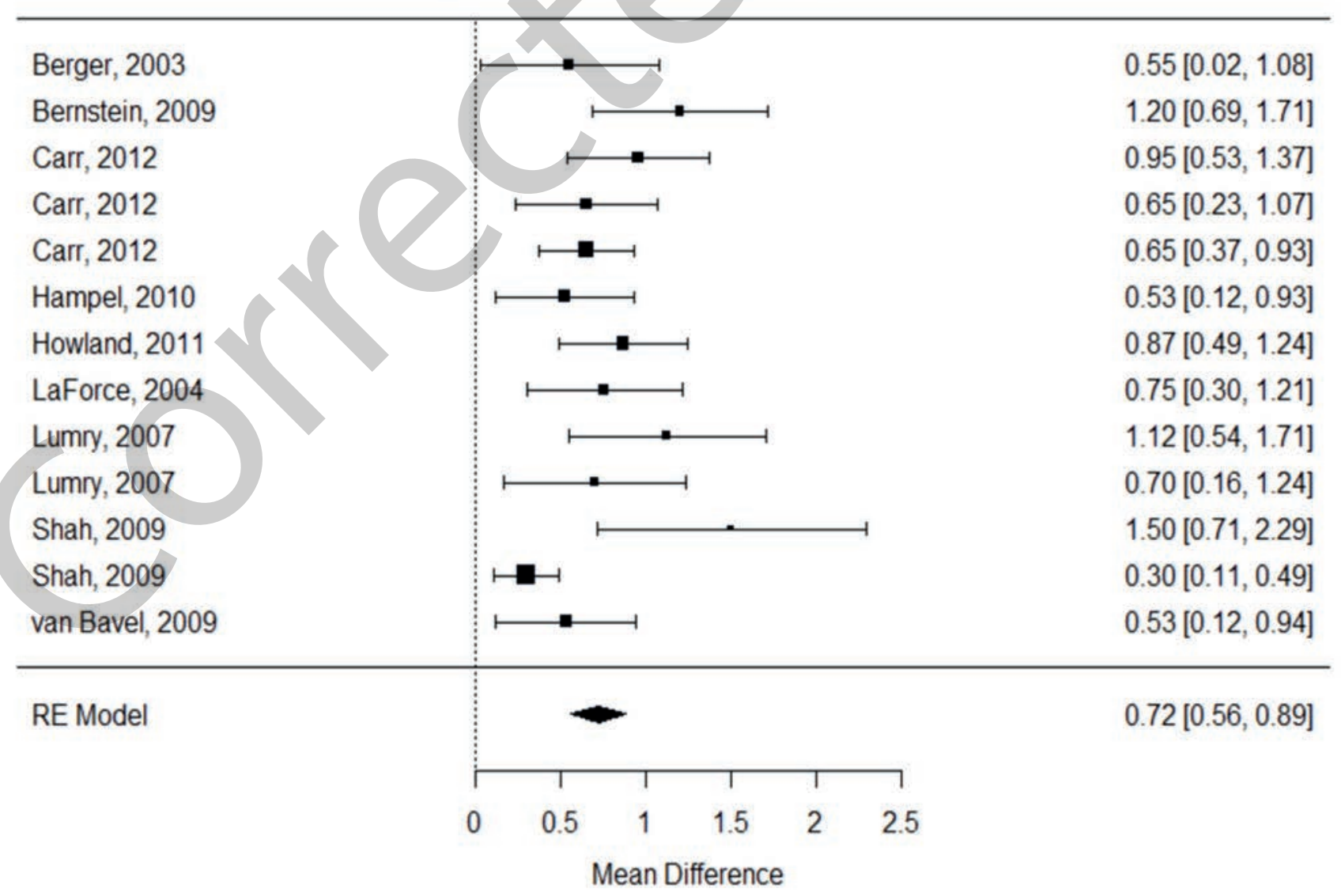


D

Adult SAR: Montelukast

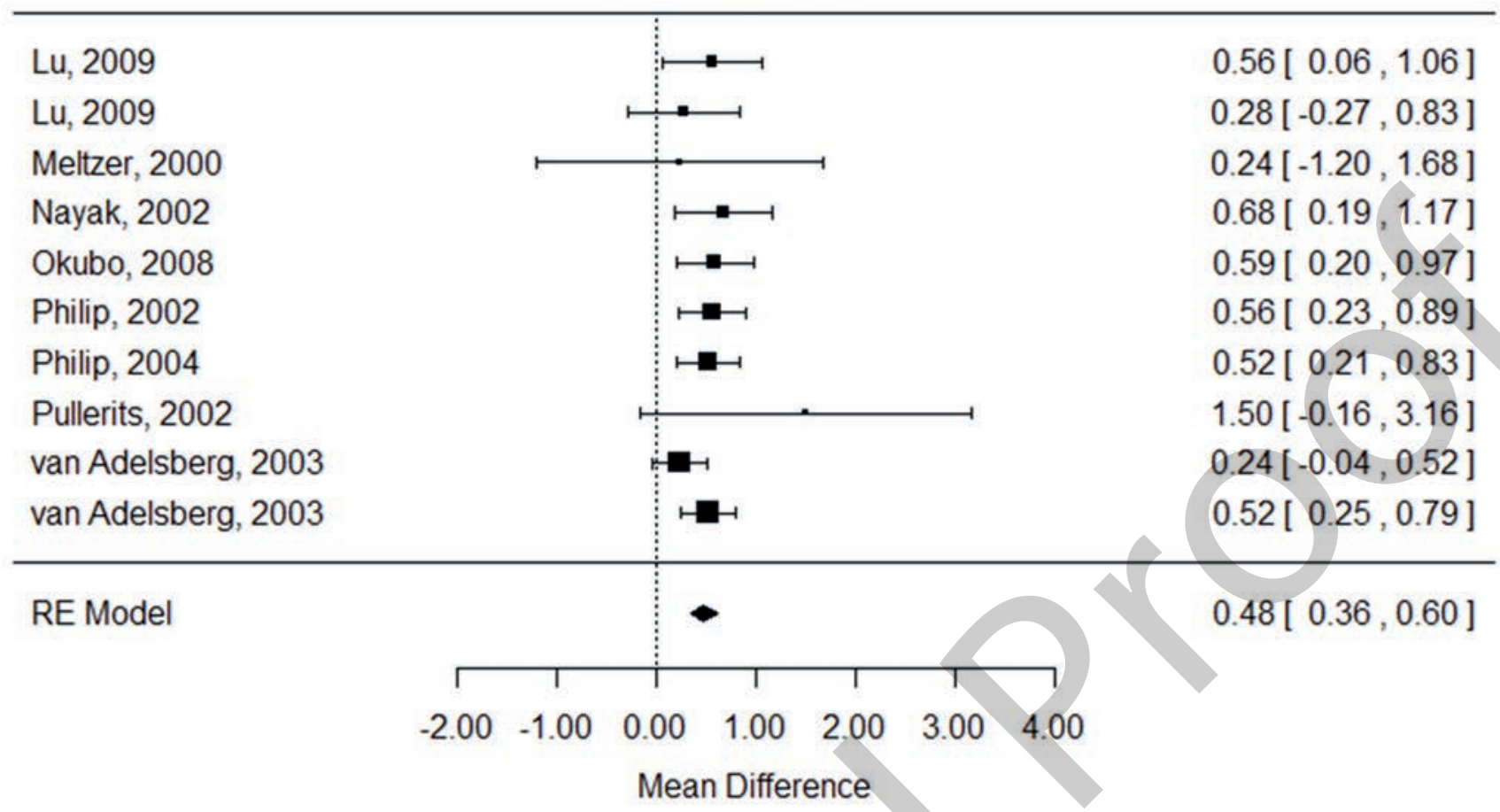

E

Adult SAR: Combo Intranasal Antihistamines/INCS

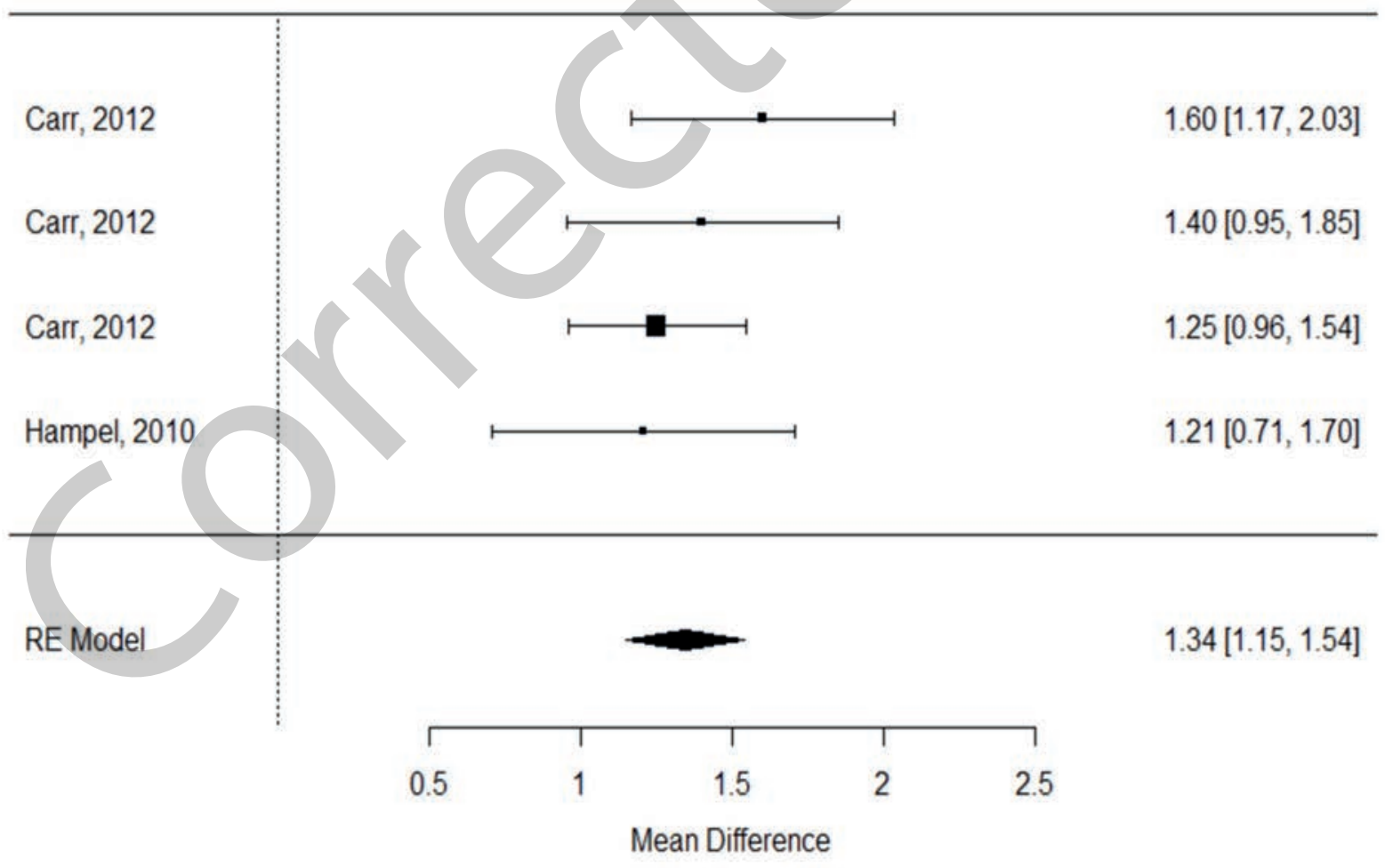


Meltzer et al.

F

Adult SAR: SLIT-Tablets

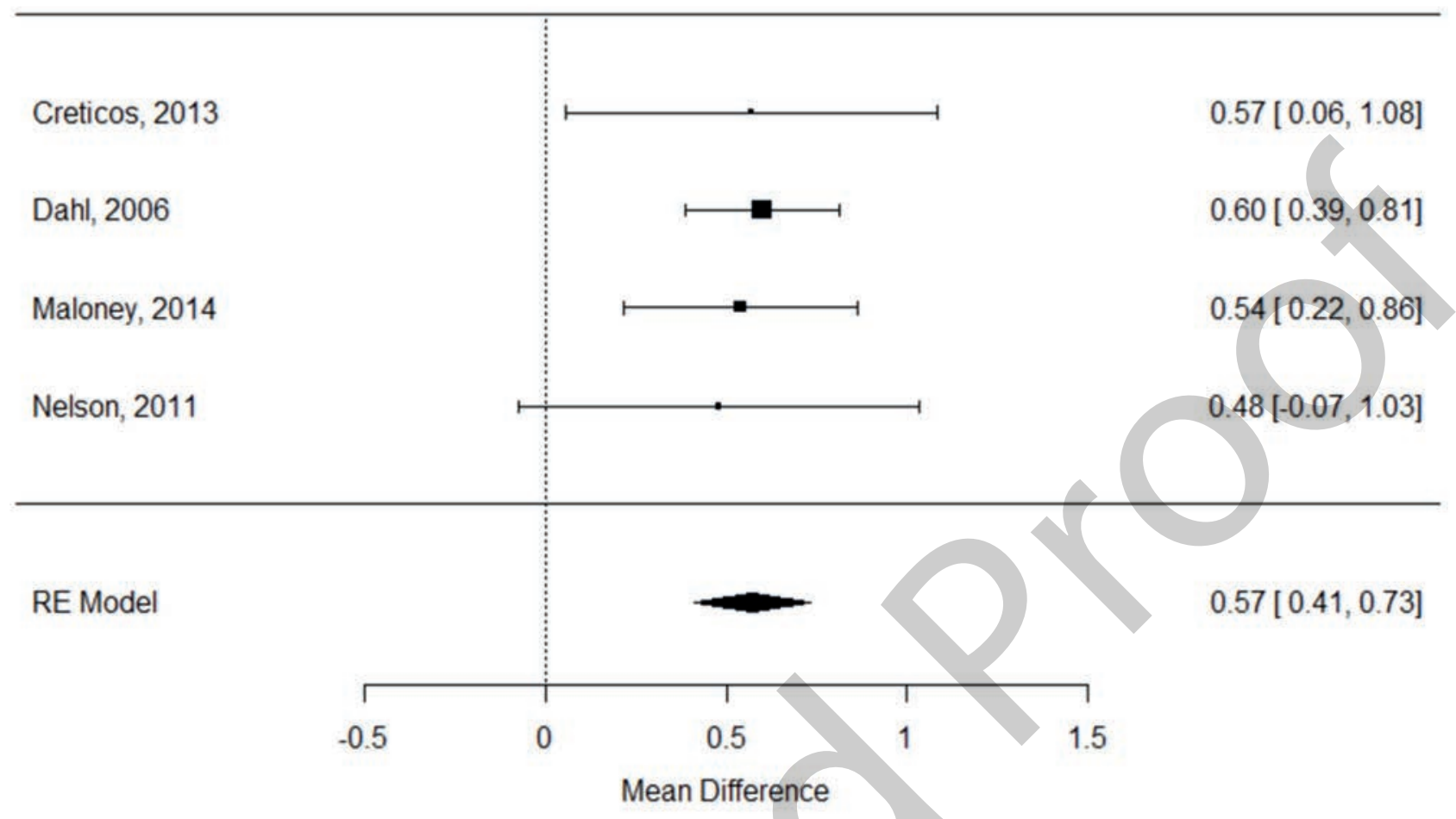

22 
Figure E2. Mean difference from placebo in total nasal symptom score in adult/adolescent perennial allergic rhinitis (PAR) for A) INCS, B) oral antihistamines, and C) SLIT-tablets. INCS, intranasal corticosteroids; SLIT, sublingual immunotherapy.

A

Adult PAR: INCS

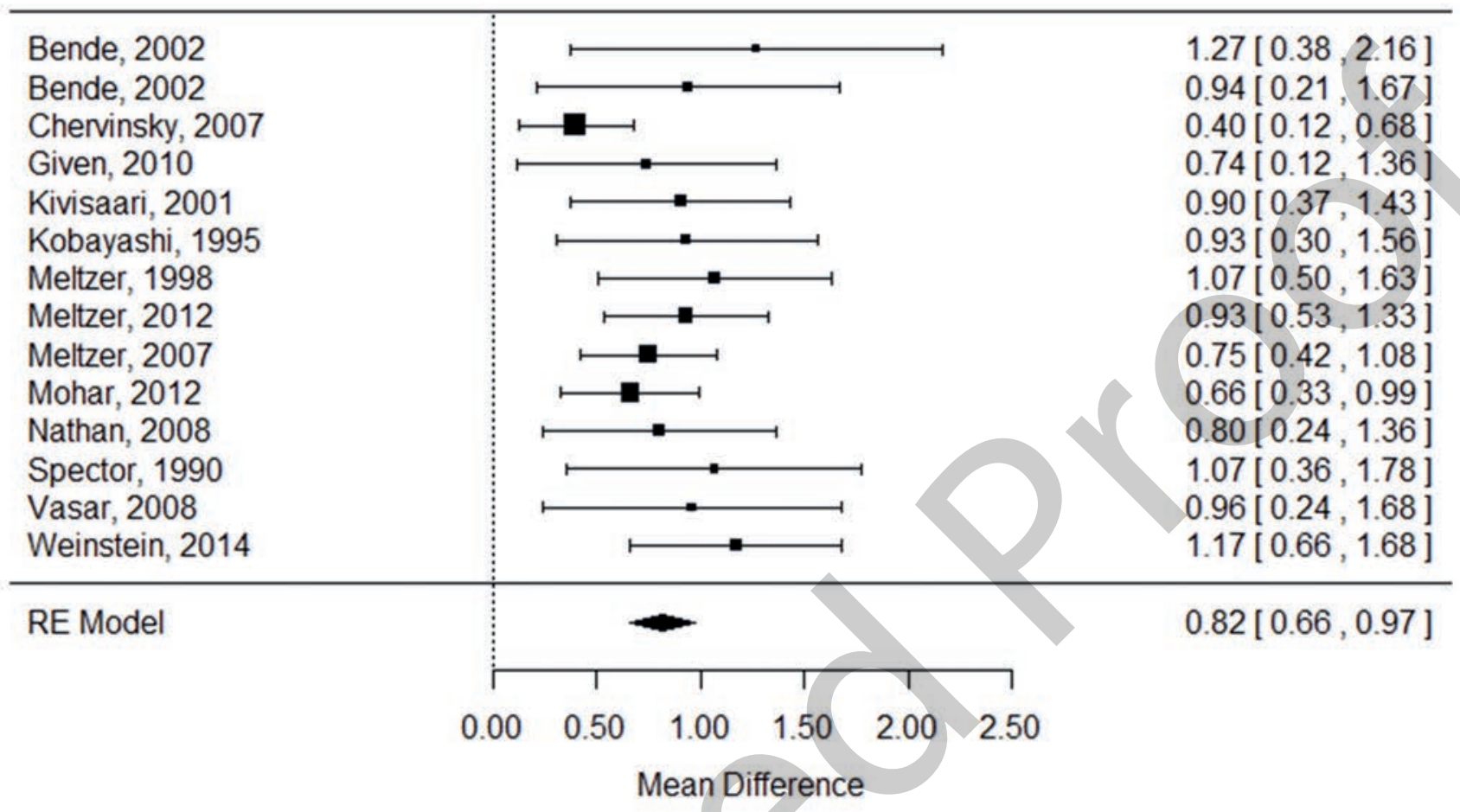

B

Adult PAR: Oral Antihistamines

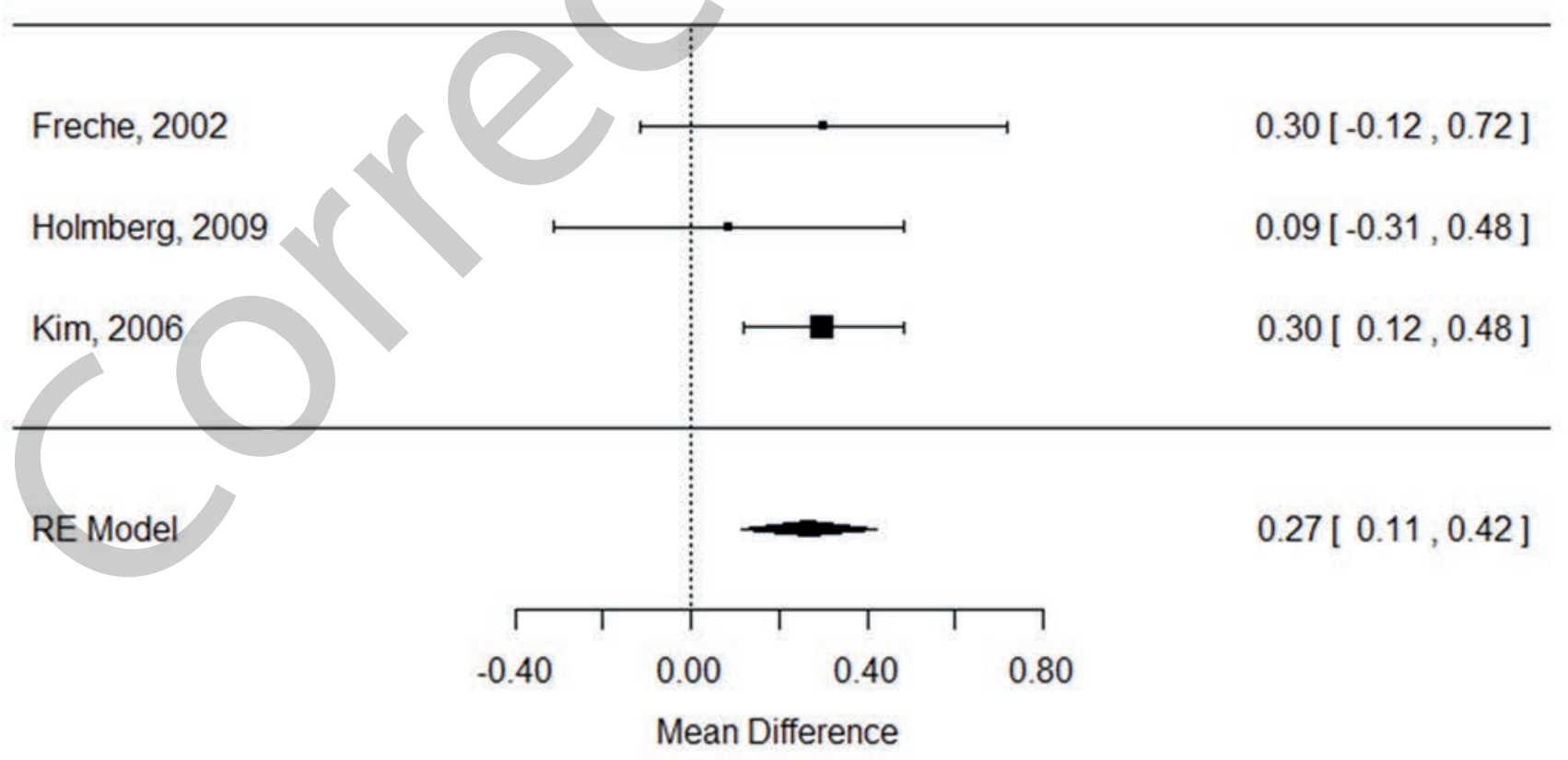


Meltzer et al.

C

Adult PAR: SLIT-Tablets

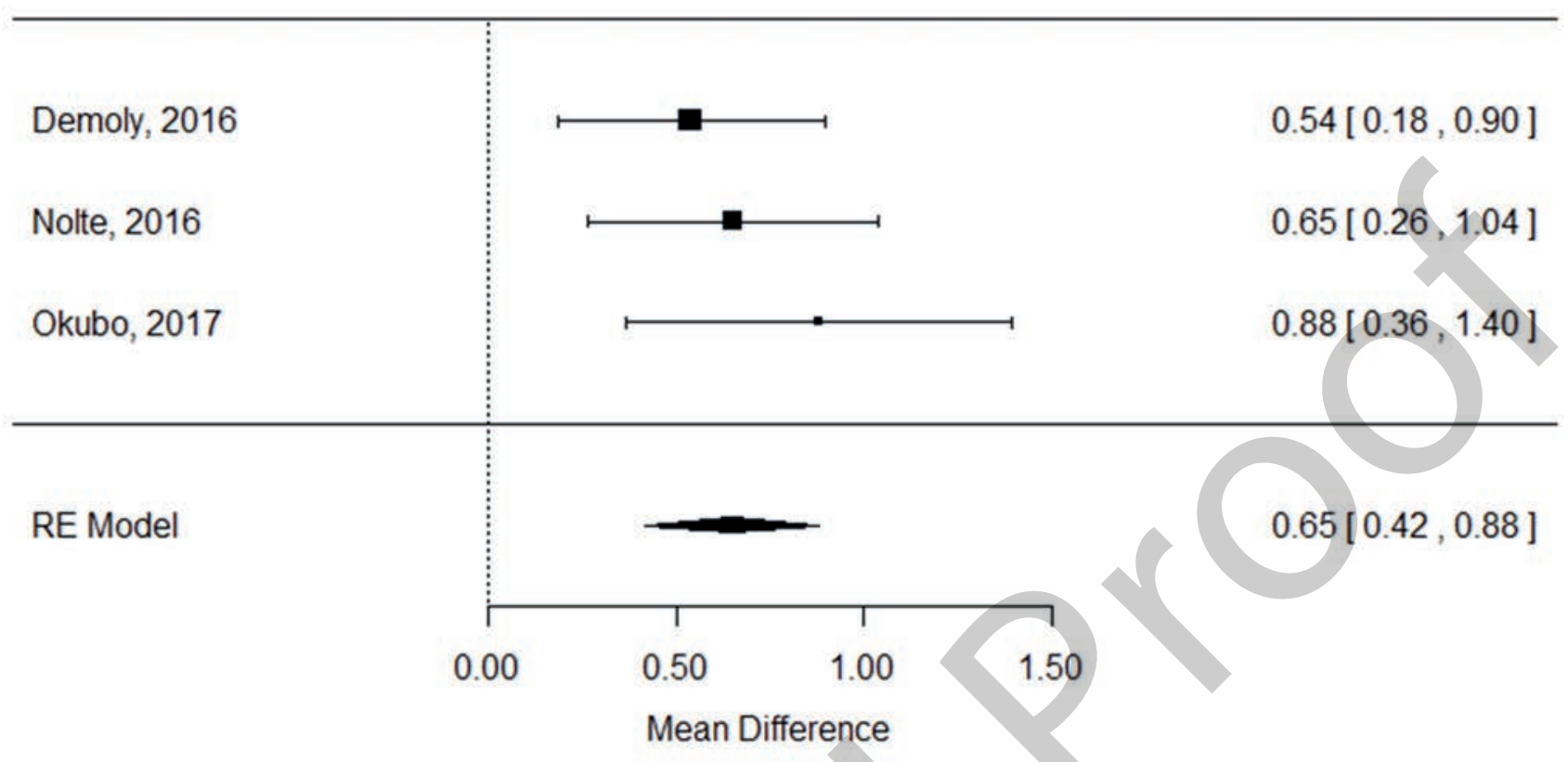

24 
Figure E3. Mean difference from placebo in total nasal symptom score in pediatric A) INCS SAR, B) SLIT-tablet SAR, and C) INCS PAR trials. INCS, intranasal corticosteroids; PAR, perennial allergic rhinitis; SAR, seasonal allergic rhinitis; SLIT, sublingual immunotherapy.

A

Pediatric SAR: INCS

Agertoft, 1993

Banov, 1996

Georges, 2014

Meltzer, 2009

Storms, 2013

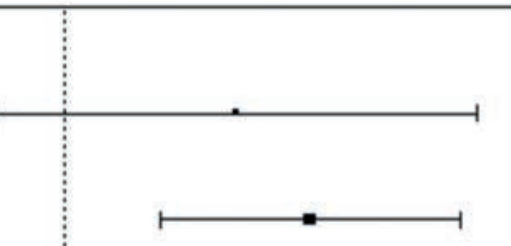

$0.77[-0.31,1.86]$

$1.11[0.43,1.78]$

$0.58[-0.31,1.47]$

$0.52[-0.05,1.09]$

$0.70[0.28,1.12]$

$\longmapsto$

$0.72[0.44,1.00]$

RE Model

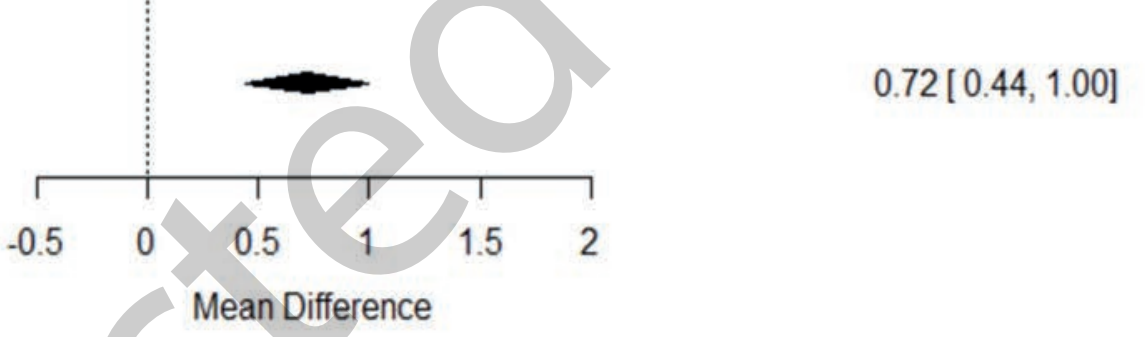

B

Pediatric SAR: SLIT-Tablets

Bufe, 2009

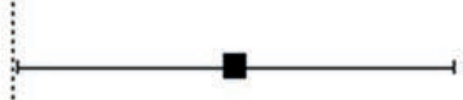

$0.48[0.01,0.95]$

Halken, 2010

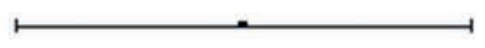

$0.59[0.10,1.08]$

RE Model 
C

Pediatric PAR: INCS

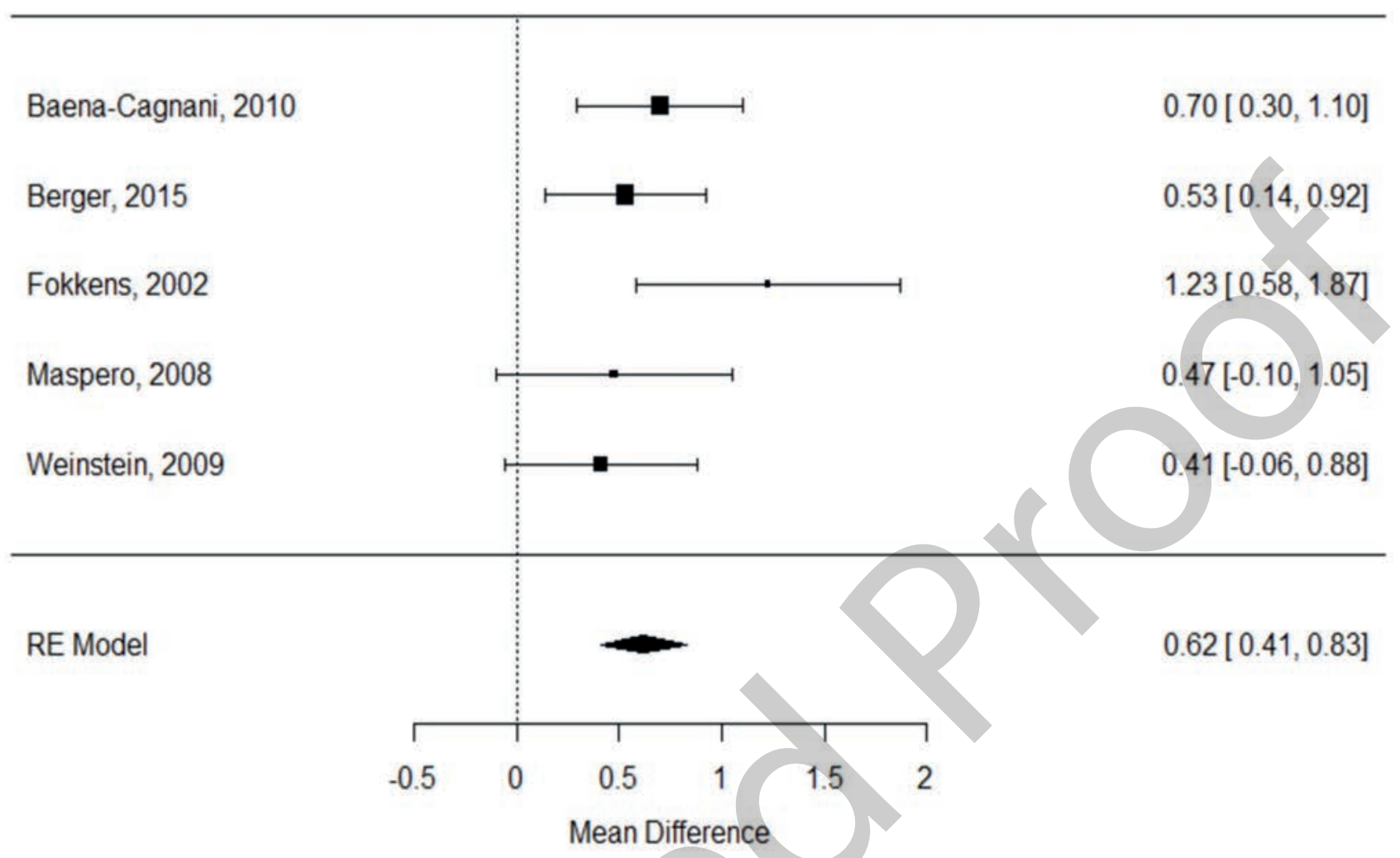


Figure E4. Funnel plots of medication classes for A) adult/adolescent seasonal allergic rhinitis, B) adult/adolescent perennial allergic rhinitis, C) pediatric seasonal allergic rhinitis, and D) pediatric perennial allergic rhinitis trials. Asymmetric plots indicate publication bias. INCS, intranasal corticosteroids; SLIT, sublingual immunotherapy.

A
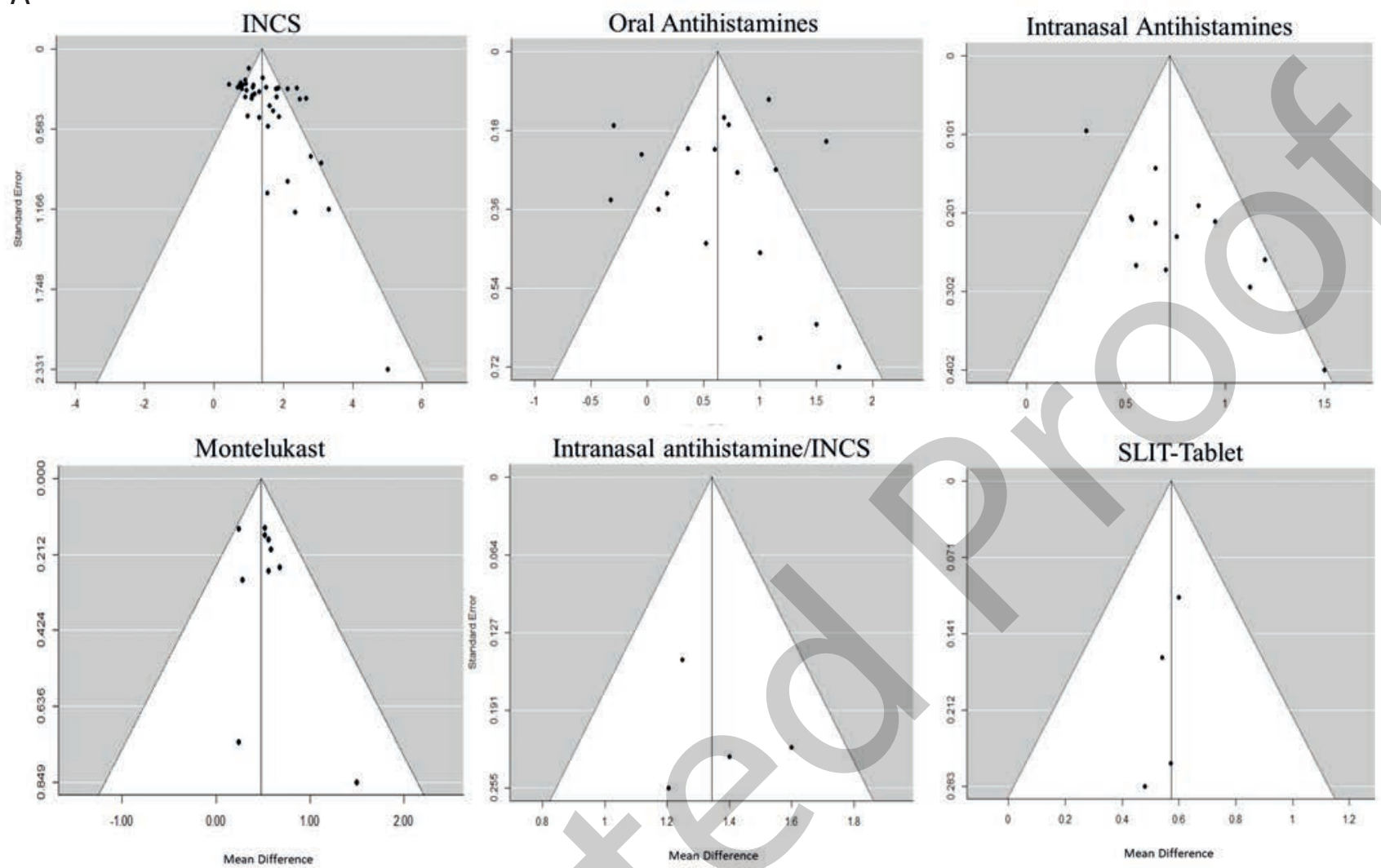

B
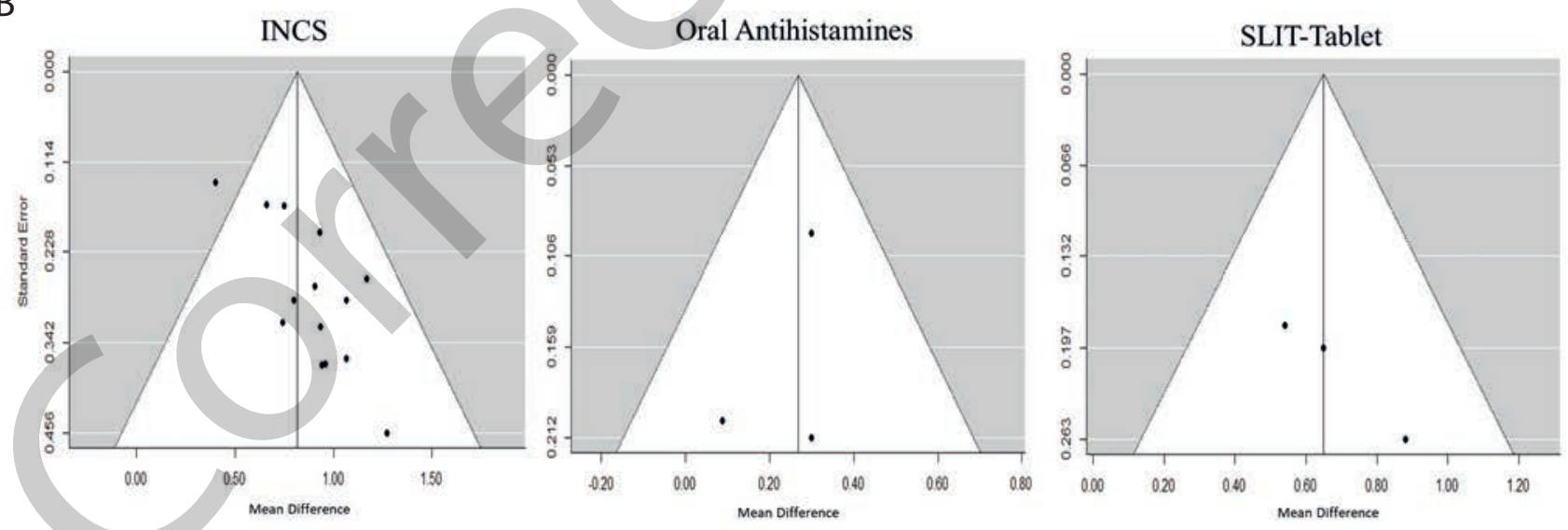

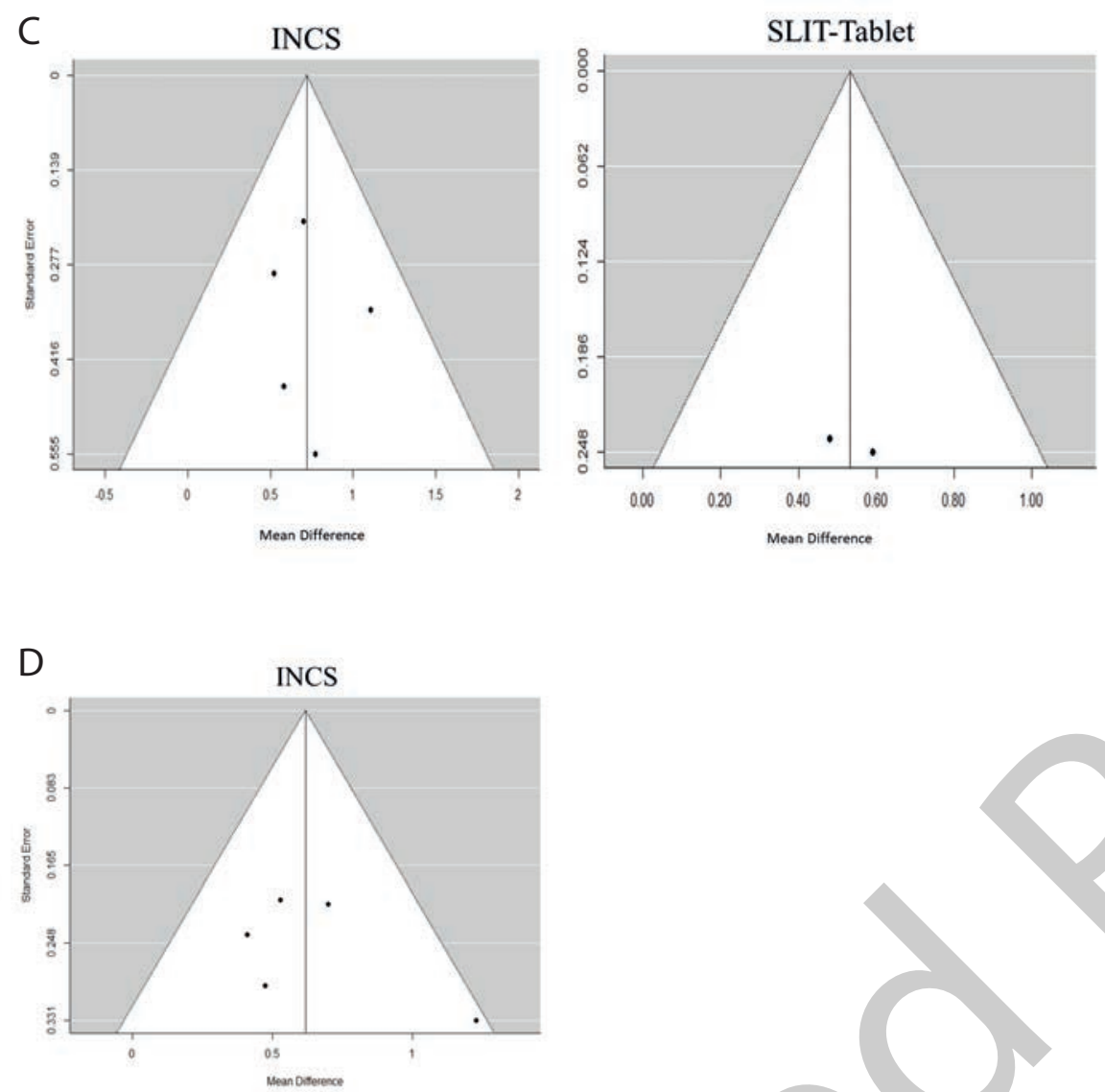


\section{References}

1. Liu G, Zhou X, Chen J, Liu F. Oral Antihistamines Alone vs in Combination with Leukotriene Receptor Antagonists for Allergic Rhinitis: A Meta-analysis. Otolaryngol Head Neck Surg. 2018;158(3):450-458.

2. Higgins J, Green S, eds. Cochrane Handbook for Systematic Reviews of Interventions Version 5.1.0 [updated March 2011]: The Cochrane Collaboration; 2011. Higgins J, Green S, eds.

3. Ma J, Liu W, Hunter A, Zhang W. Performing meta-analysis with incomplete statistical information in clinical trials. BMC Medical Research Methodology. 2008;8(1):56.

4. Andrews $C P$, Martin $B G$, Jacobs $R L$, et al. Fluticasone furoate nasal spray is more effective than fexofenadine for nighttime symptoms of seasonal allergy. Allergy Asthma Proc. 2009;30(2):128-138.

5. Anolik R. Clinical benefits of combination treatment with mometasone furoate nasal spray and loratadine vs monotherapy with mometasone furoate in the treatment of seasonal allergic rhinitis. Ann Allergy Asthma Immunol. 2008;100(3):264-271.

6. Berger WE, White MV. Efficacy of azelastine nasal spray in patients with an unsatisfactory response to loratadine. Ann Allergy Asthma Immunol. 2003;91(2):205-211.

7. Demoly P, Dreyfus I, Dhivert-Donnadieu $\mathrm{H}$, Mesbah K. Desloratadine for the treatment of cypress pollen-induced allergic rhinitis. Ann Allergy Asthma Immunol. 2009;103(3):260-266.

8. Dockhorn RJ, Bergner A, Connell JT, et al. Safety and efficacy of loratadine (Sch29851): a new non-sedating antihistamine in seasonal allergic rhinitis. Ann Allergy. 1987;58(6):407-411.

9. Ford LB, Matz J, Hankinson T, Prillaman B, Georges G. A comparison of fluticasone propionate nasal spray and cetirizine in ragweed fall seasonal allergic rhinitis. Allergy Asthma Proc. 2015;36(4):313-319.

10. Hampel F, Jr., Howland W, 3rd, Van Bavel J, Ratner P. A randomized, double-blind, placebo-controlled study comparing the efficacy and safety of ebastine $(20 \mathrm{mg}$ and $10 \mathrm{mg}$ ) to loratadine $10 \mathrm{mg}$ once daily in the treatment of seasonal allergic rhinitis. J Investig Allergol Clin Immunol. 2004; 14(1):56-63.

11. Kuna P, Bachert C, Nowacki Z, et al. Efficacy and safety of bilastine $20 \mathrm{mg}$ compared with cetirizine $10 \mathrm{mg}$ and placebo for the symptomatic treatment of seasonal allergic rhinitis: a randomized, double-blind, parallel-group study. Clin Exp Allergy. 2009;39(9):1338-1347.

12. Lu S, Malice MP, Dass SB, Reiss TF. Clinical studies of combination montelukast and loratadine in patients with seasonal allergic rhinitis. J Asthma. 2009;46(9):878-883.

13. Meltzer EO, Malmstrom K, Lu S, et al. Concomitant montelukast and loratadine as treatment for seasonal allergic rhinitis: a randomized, placebo-controlled clinical trial. J Allergy Clin Immunol. 2000;105(5):917-922.

14. Nayak AS, Philip G, Lu S, Malice MP, Reiss TF. Efficacy and tolerability of montelukast alone or in combination with loratadine in seasonal allergic rhinitis: a multicenter, randomized, double-blind, placebo-controlled trial performed in the fall. Ann Allergy Asthma Immunol. 2002;88(6):592-600.

15. Philip G, Malmstrom K, Hampel FC, et al. Montelukast for treating seasonal allergic rhinitis: a randomized, double-blind, placebo-controlled trial performed in the spring. Clin Exp Allergy. 2002;32(7):1020-1028.

16. Pradalier A, Neukirch C, Dreyfus I, Devillier P. Desloratadine improves quality of life and symptom severity in patients with allergic rhinitis. Allergy. 2007;62(11):1331-1334.

17. Ratner PH, van Bavel JH, Martin BG, et al. A comparison of the efficacy of fluticasone propionate aqueous nasal spray and loratadine, alone and in combination, for the treatment of seasonal allergic rhinitis. J Fam Pract. 1998;47(2):118-125.

18. Skassa-Brociek W, Bousquet J, Montes F, et al. Double-blind placebo-controlled study of loratadine, mequitazine, and placebo in the symptomatic treatment of seasonal allergic rhinitis. J Allergy Clin Immunol. 1988;81(4):725-730.

19. van Adelsberg J, Philip G, LaForce CF, et al. Randomized controlled trial evaluating the clinical benefit of montelukast for treating spring seasonal allergic rhinitis. Ann Allergy Asthma Immunol. 2003;90(2):214-222.

20. Freche C, Leynadier F, Horak F, et al. Mizolastine provides effective symptom relief in patients suffering from perennial allergic rhinitis: a double-blind, placebocontrolled study versus loratadine. Ann Allergy Asthma Immunol. 2002;89(3):304310.

21. Holmberg K, Tonnel AB, Dreyfus I, et al. Desloratadine relieves nasal congestion and improves quality-of-life in persistent allergic rhinitis. Allergy. 2009;64(11):1663-1670.

22. Kim K, Sussman G, Hebert J, et al. Desloratadine therapy for symptoms associated with perennial allergic rhinitis. Ann Allergy Asthma Immunol. 2006;96(3):460465.

23. Bronsky EA, Aaronson DW, Berkowitz RB, et al. Dose ranging study of mometasone furoate (Nasonex) in seasonal allergic rhinitis. Ann Allergy Asthma Immunol. 1997;79(1):51-56.

24. Bronsky EA, Dockhorn RJ, Meltzer EO, et al. Fluticasone propionate aqueous nasal spray compared with terfenadine tablets in the treatment of seasonal allergic rhinitis. J Allergy Clin Immunol. 1996;97(4):915-921.

25. Carr W, Bernstein J, Lieberman P, et al. A novel intranasal therapy of azelastine with fluticasone for the treatment of allergic rhinitis. J Allergy Clin Immunol. 2012;129(5):1282-1289.e1210.

26. Creticos P, Fireman P, Settipane $G$, et al. Intranasal budesonide aqueous pump spray (Rhinocort Aqua) for the treatment of seasonal allergic rhinitis. Rhinocort Aqua Study Group. Allergy Asthma Proc. 1998;19(5):285-294.

27. Di Lorenzo G, Gervasi F, Drago A, et al. Comparison of the effects of fluticasone propionate, aqueous nasal spray and levocabastine on inflammatory cells in nasal lavage and clinical activity during the pollen season in seasonal rhinitics. Clin Exp Allergy. 1999;29(10):1367-1377.

28. Di Lorenzo G, Pacor ML, Pellitteri ME, et al. Randomized placebo-controlled trial comparing fluticasone aqueous nasal spray in mono-therapy, fluticasone plus cetirizine, fluticasone plus montelukast and cetirizine plus montelukast for seasonal allergic rhinitis. Clin Exp Allergy. 2004;34(2):259-267.

29. Dykewicz MS, Kaiser HB, Nathan RA, et al. Fluticasone propionate aqueous nasal spray improves nasal symptoms of seasonal allergic rhinitis when used as needed (prn). Ann Allergy Asthma Immunol. 2003;91(1):44-48.

30. Findlay S, Huber F, Garcia J, Huang L. Efficacy of once-a-day intranasal administration of triamcinolone acetonide in patients with seasonal allergic rhinitis. Ann Allergy. 1992;68(3):228-232.

31. Fokkens WJ, Jogi R, Reinartz $S$, et al. Once daily fluticasone furoate nasal spray is effective in seasonal allergic rhinitis caused by grass pollen. Allergy. 2007;62(9):1078-1084.

32. Graft D, Aaronson D, Chervinsky P, et al. A placebo- and active-controlled randomized trial of prophylactic treatment of seasonal allergic rhinitis with mometasone furoate aqueous nasal spray. J Allergy Clin Immunol. 1996;98(4):724-731.

33. Hampel FC, Ratner PH, Van Bavel J, et al. Double-blind, placebo-controlled study of azelastine and fluticasone in a single nasal spray delivery device. Ann Allergy Asthma Immunol. 2010;105(2):168-173.

34. Jacobs R, Martin B, Hampel F, et al. Effectiveness of fluticasone furoate 110 microg once daily in the treatment of nasal and ocular symptoms of seasonal allergic rhinitis in adults and adolescents sensitized to mountain cedar pollen. Curr Med Res Opin. 2009;25(6):1393-1401.

35. Kaiser HB, Naclerio RM, Given J, et al. Fluticasone furoate nasal spray: a single treatment option for the symptoms of seasonal allergic rhinitis. J Allergy Clin Immunol. 2007;119(6):1430-1437.

36. Mansfield LE, Posey CR. Daytime sleepiness and cognitive performance improve in seasonal allergic rhinitis treated with intranasal fluticasone propionate. Allergy Asthma Proc. 2007;28(2):226-229.

37. Martin BG, Ratner PH, Hampel FC, et al. Optimal dose selection of fluticasone furoate nasal spray for the treatment of seasonal allergic rhinitis in adults and adolescents. Allergy Asthma Proc. 2007;28(2):216-225.

38. Meltzer EO, Jalowayski AA, Orgel HA, Harris AG. Subjective and objective assessments in patients with seasonal allergic rhinitis: effects of therapy with mometasone furoate nasal spray. J Allergy Clin Immunol. 
1998;102(1):39-49.

39. Meltzer EO, Shekar T, Teper AA. Mometasone furoate nasal spray for moderate-to-severe nasal congestion in subjects with seasonal allergic rhinitis. Allergy Asthma Proc. 2011;32(2):159-167.

40. Munk ZM, Gross GN, Hampel FC, Jr., Ratner $\mathrm{PH}$. Preseasonal, once daily triamcinolone acetonide nasal aerosol for seasonal allergic rhinitis. Ann Allergy Asthma Immunol. 1997;78(3):325-331

41. Munk ZM, LaForce C, Furst JA, et al. Efficacy and safety of triamcinolone acetonide aqueous nasal spray in patients with seasonal allergic rhinitis. Ann Allergy Asthma Immunol. 1996;77(4):277-281.

42. Okubo K, Nakashima M, Miyake N, Komatsubara M, Okuda M. Comparison of fluticasone furoate and fluticasone propionate for the treatment of Japanese cedar pollinosis. Allergy Asthma Proc. 2009;30(1):8494.

43. Prenner BM, Lanier BQ, Bernstein DI, Shekar T, Teper A. Mometasone furoate nasal spray reduces the ocular symptoms of seasonal allergic rhinitis. J Allergy Clin Immunol. 2010;125(6):1247-1253.e1245

44. Pullerits T, Praks L, Ristioja V, Lotvall J. Comparison of a nasal glucocorticoid, antileukotriene, and a combination of antileukotriene and antihistamine in the treatment of seasonal allergic rhinitis. J Allergy Clin Immunol. 2002;109(6):949-955.

45. Raphael GD, Berger WE, Prenner BM, et al. Efficacy, safety, and optimal dose selection of beclomethasone dipropionate nasal aerosol for seasonal allergic rhinitis in adolescents and adults. Curr Med Res Opin. 2013;29(10):1329-1340.

46. Ratner PH, Wingertzahn MA, van Bavel $\mathrm{JH}$, et al. Efficacy and safety of ciclesonide nasal spray for the treatment of seasonal allergic rhinitis. J Allergy Clin Immunol. 2006;118(5):1142-1148.

47. Rosenthal R, Berger W, Bronsky E, et al. TriNasal triamcinolone acetonide nasal spray 200 and 400 micrograms qd versus placebo and Nasacort triamcinolone acetonide nasal aerosol 440 micrograms qd in patients suffering from seasonal allergic rhinitis during the grass season. Am J Rhinol. 1998;12(6):427-433

48. Schenkel E, Newman KB. Therapeutic equivalence of triamcinolone acetonide hydrofluoroalkane and chlorofluorocarbon nasa inhalers in patients with seasonal allergic rhinitis. Am J Rhinol Allergy. 2013;27(2):109112.

49. Steensen $\mathrm{H}$, Lindqvist $\mathrm{N}$. Treatment of grass pollen-induced hay fever with intranasal budesonide. A double-blind clinical comparison between budesonide and placebo. Allergy. 1981;36(4):245-249.

50. Stern MA, Dahl R, Nielsen LP, Pedersen B, Schrewelius C. A comparison of aqueous suspensions of budesonide nasal spray (128 micrograms and 256 micrograms once daily) and fluticasone propionate nasal spray (200 micrograms once daily) in the treatment of adult patients with seasonal allergic rhinitis. Am J Rhinol. 1997;11(4):323330.

51. Tinkelman D, Falliers C, Gross G, et al. Multicenter evaluation of triamcinolone acetonide nasal aerosol in the treatment of adult patients with seasonal allergic rhinitis Ann Allergy. 1990;64(2 Pt 2):234-240.

52. van Bavel JH, Ratner PH, Amar NJ, et al. Efficacy and safety of once-daily treatment with beclomethasone dipropionate nasal aerosol in subjects with seasonal allergic rhinitis. Allergy Asthma Proc. 2012;33(5):386-396

53. Bende M, Carrillo T, Vona I, da Castel-Branco $M G$, Arheden L. A randomized comparison of the effects of budesonide and mometasone furoate aqueous nasal sprays on nasal peak flow rate and symptoms in perennial allergic rhinitis. Ann Allergy Asthma Immunol. 2002;88(6):617-623.

54. Chervinsky P, Kunjibettu S, Miller DL, et al. Long-term safety and efficacy of intranasal ciclesonide in adult and adolescent patients with perennial allergic rhinitis. Ann Allergy Asthma Immunol. 2007;99(1):69-76.

55. Given JT, Cheema AS, Dreykluft $T$, et al Fluticasone furoate nasal spray is effective and well tolerated for perennial allergic rhinitis in adolescents and adults. Am J Rhino Allergy. 2010;24(6):444-450.

56. Kivisaari E, Baker RC, Price MJ. Comparison of once daily fluticasone propionate aqueous nasal spray with once daily budesonide reservoir powder device in patients with perennial rhinitis. Clin Exp Allergy. 2001;31(6):855-863.

57. Kobayashi RH, Beaucher WN, Koepke JW, et al. Triamcinolone acetonide aqueous nasal spray for the treatment of patients with perennial allergic rhinitis: a multicenter, randomized, double-blind, placebo-controlled study. Clin Ther. 1995;17(3):503-513.

58. Meltzer EO. Clinical and antiinflammatory effects of intranasal budesonide aqueous pump spray in the treatment of perennial allergic rhinitis. Ann Allergy Asthma Immunol. 1998;81(2):128-134.

59. Meltzer EO, Jacobs RL, LaForce CF, et al. Safety and efficacy of once-daily treatment with beclomethasone dipropionate nasal aerosol in subjects with perennial allergic rhinitis. Allergy Asthma Proc. 2012;33(3):249-257.

60. Meltzer EO, Kunjibettu S, Hall N, et al. Efficacy and safety of ciclesonide, 200 microg once daily, for the treatment of perennial allergic rhinitis. Ann Allergy Asthma Immunol. 2007;98(2):175-181.

61. Mohar D, Berger WE, Laforce C, et al. Efficacy and tolerability study of ciclesonide nasa aerosol in patients with perennial allergic rhinitis. Allergy Asthma Proc. 2012;33(1):1926.

62. Nathan RA, Berger W, Yang W, et al. Effect of once-daily fluticasone furoate nasal spray on nasal symptoms in adults and adoles cents with perennial allergic rhinitis. Ann Allergy Asthma Immunol. 2008;100(5):497-
505

63. Spector S, Bronsky E, Chervinsky P, et al. Multicenter, double-blind, placebo-controlled trial of triamcinolone acetonide nasal aerosol in the treatment of perennial allergic rhinitis. Ann Allergy. 1990:64(3):300305 .

64. Vasar M, Houle PA, Douglass JA, et al. Fluticasone furoate nasal spray: effective monotherapy for symptoms of perennial allergic rhinitis in adults/adolescents. Allergy Asthma Proc. 2008;29(3):313-321.

65. Weinstein SF, Andrews CP, Shah SR, et al. Long-term efficacy and safety of once-daily treatment with beclomethasone dipropionate nasal aerosol. Allergy Asthma Proc. 2014;35(4):323-331.

66. Okubo K, Baba K. Therapeutic effect of montelukast, a cysteinyl leukotriene receptor 1 antagonist, on Japanese patients with seasonal allergic rhinitis. Allergol Int. 2008;:57(3):247-255

67. Philip G, Nayak AS, Berger WE, et al. The effect of montelukast on rhinitis symptoms in patients with asthma and seasonal allergic rhinitis. Curr Med Res Opin. 2004:20(10):1549-1558.

68. van Adelsberg J, Philip G, Pedinoff AJ, et al. Montelukast improves symptoms of seasonal allergic rhinitis over a 4-week treatment period. Allergy. 2003;58(12):12681276.

69. Patel P, Philip G, Yang W, et al. Randomized, double-blind, placebo-controlled study of montelukast for treating perennial allergic rhinitis. Ann Allergy Asthma Immunol. 2005;95(6):551-557.

70. Bernstein JA, Prenner B, Ferguson BJ, et al. Double-blind, placebo-controlled trial of reformulated azelastine nasal spray in patients with seasonal allergic rhinitis. Am J Rhinol Allergy. 2009;23(5):512-517.

71. Howland WC, Amar NJ, Wheeler W, Sacks H. Efficacy and safety of azelastine $0.15 \%$ nasal spray administered once daily in patients with allergy to Texas mountain cedar pollen. Int Forum Allergy Rhinol. 2011;1(4):275279.

72. LaForce CF, Corren J, Wheeler WJ, Berger WE. Efficacy of azelastine nasal spray in seasonal allergic rhinitis patients who remain symptomatic after treatment with fexofenadine. Ann Allergy Asthma Immunol. 2004:93(2):154-159.

73. Lumry W, Prenner B, Corren J, Wheeler W. Efficacy and safety of azelastine nasal spray at a dose of 1 spray per nostril twice daily. Ann Allergy Asthma Immunol. 2007;99(3):267-272.

74. Shah S, Berger W, Lumry W, et al. Efficacy and safety of azelastine $0.15 \%$ nasal spray and azelastine $0.10 \%$ nasal spray in patients with seasonal allergic rhinitis. Allergy Asthma Proc. 2009:30(6):628-633.

75. Shah SR, Nayak A, Ratner $P_{\text {, Roland } P,}$ Michael Wall G. Effects of olopatadine hydrochloride nasal spray $0.6 \%$ in the treatment of seasonal allergic rhinitis: a phase III, multicenter, randomized, dou- 
ble-blind, active- and placebo-controlled study in adolescents and adults. Clin Ther 2009;31(1):99-107.

76. van Bavel J, Howland WC, Amar NJ, Wheeler W, Sacks H. Efficacy and safety of azelastine $0.15 \%$ nasal spray administered once daily in subjects with seasonal allergic rhinitis Allergy Asthma Proc. 2009;30(5):512-518.

77. Nathan RA, Finn AF, Jr., LaForce $C$, et al. Comparison of cetirizine-pseudoephedrine and placebo in patients with seasonal allergic rhinitis and concomitant mild-tomoderate asthma: randomized, doubleblind study. Ann Allergy Asthma Immunol. 2006;97(3):389-396.

78. Agertoft L, Wolthers OD, Fuglsang G, Pedersen S. Nasal powder administration of budesonide for seasonal rhinitis in children and adolescents. Pediatr Allergy Immunol. 1993:4(3):152-156.

79. Banov $\mathrm{CH}$, Silvers WS, Green AW, et al. Placebo-controlled, double-blind study of the efficacy and safety of triamcinolone acetonide aerosol nasal inhaler in pediatric patients with seasonal allergic rhinitis. Clin Ther. 1996;18(2):265-272.

80. Georges G, Kim KT, Ratner P, Segall N, Qiu C Effect of intranasal triamcinolone acetonide on basal hypothalamic-pituitary-adrena axis function in children with allergic rhinitis. Allergy Asthma Proc. 2014;35(2):163-170.

81. Meltzer EO, Lee J, Tripathy I, et al. Efficacy and safety of once-daily fluticasone furoate nasal spray in children with seasonal allergic rhinitis treated for 2 wk. Pediatr Allergy Immunol. 2009;20(3):279-286.

82. Storms WW, Segall N, Mansfield LE, et al. Efficacy and safety of beclomethasone dipropionate nasal aerosol in pediatric patients with seasonal allergic rhinitis. Ann Allergy Asthma Immunol. 2013;111(5):408414.e401.

83. Baena-Cagnani CE, Patel P. Efficacy and long-term safety of mometasone furoate nasal spray in children with perennial allergic rhinitis. Curr Med Res Opin.
2010;26(9):2047-2055

84. Berger $W E$, Jacobs RL, Amar NJ, et al. Efficacy and safety of beclomethasone dipropionate nasal aerosol in children with perennial allergic rhinitis. Ann Allergy Asthma Immunol. 2015;115(2):130-136.

85. Fokkens WJ, Cserhati E, dos Santos JM, et al. Budesonide aqueous nasal spray is an effective treatment in children with perennial allergic rhinitis, with an onset of action within 12 hours. Ann Allergy Asthma Immunol. 2002;89(3):279-284.

86. Maspero JF, Rosenblut A, Finn A, Jr., et al. Safety and efficacy of fluticasone furoate in pediatric patients with perennial allergic rhinitis. Otolaryngol Head Neck Surg. 2008;138(1):30-37

87. Weinstein S, Qaqundah P, Georges G, Nayak A. Efficacy and safety of triamcinolone acetonide aqueous nasal spray in children aged 2 to 5 years with perennial allergic rhinitis: a randomized, double-blind, placebo-controlled study with an open-label extension. Ann Allergy Asthma Immunol. 2009;102(4):339-347.

88. Razi C, Bakirtas A, Harmanci K, Turktas I, Erbas D. Effect of montelukast on symptoms and exhaled nitric oxide levels in 7- to 14-year-old children with seasonal allergic rhinitis. Ann Allergy Asthma Immunol. 2006;97(6):767-774.

89. Meltzer EO, Blaiss M, Fairchild CJ. Comprehensive report of olopatadine $0.6 \%$ nasal spray as treatment for children with seasonal allergic rhinitis. Allergy Asthma Proc. 2011;32(3):213-220.

90. BergerW, Meltzer EO, Amar N, et al. Efficacy of MP-AzeFlu in children with seasonal allergic rhinitis: Importance of paediatric symptom assessment. Pediatr Allergy Immunol. 2016;27(2):126-133

91. Creticos PS, Maloney J, Bernstein Dl, et al. Randomized controlled trial of a ragweed allergy immunotherapy tablet in North American and European adults. J Allergy Clin Immunol. 2013;131(5):1342-1349 e1346.

92. Dahl R, Kapp A, Colombo G, et al. Efficacy and safety of sublingual immunotherapy with grass allergen tablets for seasonal allergic rhinoconjunctivitis. J Allergy Clin Immunol. 2006;118(2):434-440.

93. Maloney J, Bernstein DI, Nelson H, et al. Efficacy and safety of grass sublingual immunotherapy tablet, MK-7243: a large randomized controlled trial. Ann Allergy Asthma Immunol. 2014;112(2):146-153. e142.

94. Nelson HS, Nolte H, Creticos P, et al. Efficacy and safety of timothy grass allergy immunotherapy tablet treatment in North American adults. J Allergy Clin Immunol. 2011;127(1):72-80 e72.

95. Demoly P, Emminger W, Rehm D, et al. Effective treatment of house dust miteinduced allergic rhinitis with 2 doses of the SQ HDM SLIT-tablet: Results from a randomized double-blind, placebo-controlled phase III trial. J Allergy Clin Immunol 2016;137(2):444-451.

96. Nolte $\mathrm{H}$, Bernstein DI, Nelson HS, et al. Efficacy of house dust mite SLIT-tablet in North American adolescents and adults in a randomized, placebo-controlled trial. J Allergy Clin Immunol. 2016;138(6):16311638.

97. Okubo K, Masuyama K, Imai T, et al. Efficacy and safety of the SQ house dust mite sublingual immunotherapy tablet in Japanese adults and adolescents with house dust mite-induced allergic rhinitis. J Allergy Clin Immunol. 2017;139(6):1840-1848.e1810.

98. Bufe A, Eberle P, Franke-Beckmann E, et al. Safety and efficacy in children of an SQ-standardized grass allergen tablet for sublingual immunotherapy. J Allergy Clin Immunol. 2009;123(1):167-173 e167.

99. Halken S, Agertoft L, Seidenberg J, et al. Five-grass pollen 300IR SLIT tablets: efficacy and safety in children and adolescents. Pediatr Allergy Immunol. 2010;21(6):970976 